\title{
Comparative effect of thermo/pH-responsive polymer-coated gold nanocages and hollow nanostars on chemo-photothermal therapy of breast cancer cells
}

\author{
Asrin Pakravan ${ }^{1}$, Mehdi Azizi ${ }^{2}$, Fariborz Rahimi ${ }^{3}$, Farhad Bani ${ }^{2}$, Farideh Mahmoudzadeh ${ }^{4}$, Roya Salehi ${ }^{5^{*}}$ (i) and \\ Mehrdad Mahkam ${ }^{1 *}$
}

*Correspondence:

salehiro@tbzmed.ac.ir;

mahkam@azaruniv.edu

${ }^{1}$ Chemistry Department,

Faculty of Science,

Azarbaijan Shahid Madani

University, Tabriz, Iran ${ }^{5}$ Drug

Applied Research Center

and Department of Medical

Nanotechnology, Faculty

of Advanced Medical

Science, Tabriz University

of Medical Science,

5166614733 Tabriz, Iran

Full list of author information

is available at the end of the article

\begin{abstract}
Background: Combination chemo-photothermal therapy appears to be one of the next generations of cancer treatment. In this study hollow gold nanostars (HGNSs) and gold nanocages (GNCs) were synthesized and stabilized with thermo$\mathrm{pH}$-sensitive thiol-end capped $\mathrm{ABC}$ triblock copolymer poly(acrylic acid)-b-poly( $\mathrm{N}$ isopropylacrylamide)-b-poly (e-caprolactone)-SH; PAA-b-PNIPAAm-b-PCL-SH (GNSs@ Pol). Doxorubicin (Dox) was conjugated to the GNSs@Pol nanostructures via ionic interaction, covalent attachment and hydrogen bonding (GNSs@Dox-Pol). The physicochemical characteristics of prepared GNSs@Pol and GNSs were assessed using dynamic light scattering (DLS), transmission electron microscopy (TEM) and zeta potential techniques. Cytocompatibility of the GNSs@Pol was studied by hemolysis assay and MTT assay. The chemo-photothermal therapy (PTT) potential of GNSs@Dox-Pol was compared on MCF7 cells using MTT assay, cell cycle, DAPI staining and Annexin-V apoptosis assay techniques.
\end{abstract}

Results: Cell internalization results showed an almost complete uptake of GNSs@Pol by MCF-7 cells in the first $3 \mathrm{~h}$ of treatment. The heat generation measurement results showed that both of GNSs have a potential for light to heat conversion $\left(\triangle T=23-27^{\circ} \mathrm{C}\right)$ and HGNSs demonstrated better efficiency than GNCs after 10-min exposure to NIR irradiation. Following chemo-photothermal treatment, the highest cell mortality (90\%) and apoptotic effects (97\% apoptosis) were observed in HGNSs@Dox-Pol received laser irradiation treatment group.

Conclusions: This work highlights the potential application of designed GNSs@DoxPol in a combinational chemo-PTT to treat breast cancer cells.

Keywords: Photothermal therapy, Anisotropic gold nanostructure, Plasmon surface resonance, Combination therapy

(c) The Author(s), 2021. Open Access This article is licensed under a Creative Commons Attribution 4.0 International License, which permits use, sharing, adaptation, distribution and reproduction in any medium or format, as long as you give appropriate credit to the original author(s) and the source, provide a link to the Creative Commons licence, and indicate if changes were made. The images or other third party material in this article are included in the article's Creative Commons licence, unless indicated otherwise in a credit line to the material. If material is not included in the article's Creative Commons licence and your intended use is not permitted by statutory regulation or exceeds the permitted use, you will need to obtain permission directly from the copyright holder. To view a copy of this licence, visit http:// creativecommons.org/licenses/by/4.0/. The Creative Commons Public Domain Dedication waiver (http://creativecommons.org/publi cdomain/zero/1.0/) applies to the data made available in this article, unless otherwise stated in a credit line to the data. 


\section{Introduction}

In the clinic, major therapeutic candidates for cancer therapy include surgical resection, immunotherapy, chemotherapy, radiotherapy, gene therapy, and thermotherapy. However, in many cases, the mentioned treatment regimens are not effective and have many associated side effects (Dianat-Moghadam 2018, 2020). For this purpose smart nanoparticles have been generally used as vehicles for delivering anti-proliferative drugs to target cancer cells (Chaudhuri 2009; Chekhun 2009). Previous studies have shown that the mentioned methods are generally deemed less effective in comparison with the combination therapy approach (Jaffray 2012; Li 2013). Besides, combination therapy has a synergistic effect and reduced side effects in cancer therapy. Therefore, in order to improve treatment outcomes, the use of multi-modality is an essential step in cancer therapy (Yap et al. 2013; Blagosklonny 2004). Compared to separate photothermal therapy (PTT) and chemotherapy, combined chemo-photothermal therapy demonstrates significantly improved efficacy in treatment. The reason is more precise control of drug-release patterns and enhanced cytotoxicity of chemotherapy drugs at higher temperatures. A prevalent restriction in regular chemotherapy is a decrease in therapeutic efficacy due to the drug resistance phenomenon (Hauck 2008; Dykman and Khlebtsov 2012), which can be compensated by PTT.

Among different types of nanoparticles, gold nanostructures (GNSs) offer multipurpose structures for the creation of smart nanoparticles. GNSs are good candidates for combination therapy since they can deliver chemotherapy and create cytotoxic heat by PTT for the targeted cancerous cells. GNSs biocompatibility, tunable localized surface plasmon resonance (LSPR), and active surface to functionalization, make them potent nanocarriers for the targeted delivery of numerous anticancer drugs. Moreover, GNSs exhibit fine-tunable LSPR, providing a critical role in optimizing photothermal conversion (Broek 2011). Between a diverse set of GNSs, hollow interior structures, such as hollow gold nanostars (HGNSs) and gold nanocages (GNCs), have been of particular interest for chemo-PPT due to their high surface-to-volume ratio, strong light-heat conversion features, and PTT efficiency due to having multiple sharp spikes as well as high capabilities for drug loading (Melancon et al. 2011; Chen 2007; Zheng 2016; Hao 2007; Halas 2010; Yavuz 2009). The hollow and porous structure of these GNSs can lead to drug leakage into the target sites from early stages (Wang 2014). Besides the mentioned advantages, HGNSs and GNCs have critical challenges such as poor stability and short blood circulation time to use as a cancer therapeutic agent (Mura et al. 2013; Yang 2013). To overcome these problems, modification of HGNSs and GNCs using polymer hybrid systems is one of the suitable strategies.

The design of conjugated HGNSs and GNCs with amphiphilic copolymers can lead to an increase in their stability. This can also provide a unique and tailorable platform for the targeted delivery of chemotherapeutic drugs in combination with PTT. In the stimuli-responsive polymeric systems, the cargo can be released by physical (light, sound, pressure, temperature, electricity, or magnetic field) or chemical stimulations $(\mathrm{pH}$, ions composition or activation by specific molecules) of the environment (Ding and Li 2017; Xiang 2017). GNSs with generated hyperthermia through NIR laser irradiation accelerated the release of anticancer drugs into the target sites (Halas 2010; Gao 2012). 
In the present work, we aimed to engineer a novel combination system that benefits from the therapeutic efficacy of HGNSs and GNCs as photothermal transducers and doxorubicin (Dox) as an antitumor drug. At first, GNSs were synthesized and stabilized by covering their surface with a dual thermo-pH-sensitive micelle system (GNSs@Pol) composed of poly (acrylic acid)-b-poly ( $N$-isopropyl acrylamide)-b-poly(ecaprolactone)-SH; (PAA-b-PNIPAAm-b-PCL-SH)] (Abbasian 2017). Then Dox was conjugated to GNSs@Pol via ionic interaction hydrogen and amid bonding. Dox release from the GNSs@Dox-Pol micelle was accelerated under mild acidic conditions (tumor cells endosome) and excitation with near-infrared (NIR) laser. In the second step, the chemo-photothermal therapy efficacy of HGNSs@Dox-Pol and GNCs@Dox-Pol PTT in MCF-7 breast cancer cells was compared.

\section{Materials and methods}

\section{Materials}

Sodium borohydride $\left(\mathrm{NaBH}_{4}\right)$, L-ascorbic acid (AA), and silver nitrate $\left(\mathrm{AgNO}_{3}\right)$ were purchased from local chemical companies. Cetyl trimethylammonium bromide (CTAB, 99\%), poly(vinyl pyrrolidone) (PVP, powder, average $\mathrm{Mw} \approx 40,000$ ) and $\mathrm{HAuCl}_{4} \cdot 3 \mathrm{H}_{2} \mathrm{O}$ (99.9\%) were bought from Sigma-Aldrich Co. (St. Louis, MO, USA). Ethylene glycol, $\mathrm{Na}_{2} \mathrm{~S} .9 \mathrm{H}_{2} \mathrm{O}$, acetone, ethanol (reagent grade) were purchased from Merck. Doxorubicin hydrochloride was purchased from Zhejiang Hisun Pharmaceutical Co., Ltd., Taizhou, China. 3-(4,5-dimethylthiazol-2-yl)-2,5-diphenyltetrazolium bromide (MTT), 4',6diamidino-2-phenylindole (DAPI), fetal bovine serum (FBS), Roswell Park Memorial Institute 1640 growth medium (RPMI), propidium iodide (PI), rhodamine $\mathrm{B}$, and ribonuclease A were obtained from Gibco BRL Life. Millipore Synergy ultrapure water (DI) of resistivity $=18.2 \mathrm{M} \Omega \mathrm{cm}^{-1}$ was used for the synthesis of HGNSs and GNCs.

\section{Instrumentation}

Absorption spectra were recorded using double beam PC 1650 UV-Vis (SHIMADZU, Kyoto, Japan) spectrometer. Morphology and particle size of gold nanostructures were analyzed by transmission electron microscopy (TEM, LEO 906 at $100 \mathrm{kV}$ acceleration voltages, Zeiss, Germany). To obtain average nanoparticle size and zeta potential, dynamic laser scattering was used (Zetasizer Nano, Malvern, UK). Inductively coupled plasma mass spectrometry (ICP-MS; Elan 6100DRC-e, Perkin-Elmer, Waltham, MA, USA) was used for determination of Au ion concentration and quantification of GNSs internalization by MCF-7 cells.

\section{Preparation of gold nanostructures}

\section{Synthesis of $A B C$ triblock copolymer}

Thiol-end capped ABC triblock copolymer poly(acrylic acid)-b-poly $(N$ isopropylacrylamide)-b-poly (e-caprolactone)-SH; PAA-b-PNIPAAm-b-PCL-SH was synthesized in four steps with combination of ring-opening polymerization and RAFT polymerization. At first bis(2-hydroxyethyl) disulfide was synthesized with dimerization of mercaptoethanol. Then The (PCL-S) 2 was synthesized by ring-opening polymerization (ROP) of $\varepsilon$-caprolactone monomer using bis(2-hydroxyethyl)disulfide as an initiator. Due to its applicability to all forms of vinyl monomers the RAFT procedure used for the 
synthesis of ABC triblock copolymers. Therefore (PAA-b-PNIPAAm-b-PCL-S)2 pentablock copolymer was synthesized through the RAFT technique and finally thiol-end capped copolymer (PAA-b-PNIPAAm-b-PCL-SH) was obtained by breaking S-S bound of copolymer with dithiothreitol (DTT) method. The synthesis protocol of all four step was explained in detailed in previously published articles (Abbasian 2017; Mahmoodzadeh 2017).

\section{Synthesis of gold nanocages (GNCs)}

$\mathrm{Au}-\mathrm{Ag}$ alloyed nanocages were synthesized in the two-step procedure described previously (Skrabalak 2007). First, Ag nanocubes were prepared by addition of poly(vinyl pyrrolidone) (PVP, $10 \mathrm{ml}, 300 \mathrm{mg} / \mathrm{ml}$ in $\mathrm{EG}, \mathrm{MW} \approx 40000$ ) to EG in an oil bath as precursor solution. Then $\mathrm{AgNO}_{3}(2.5 \mathrm{~mL}, 282 \mathrm{mM}$ in EG) slowly was injected into the heated solution. The obtained Ag nanocubes were converted to GNCs via a galvanic replacement reaction between silver and gold nanoparticles (Wang 2014; Khlebtsov 2013). An aqueous solution of $\mathrm{HAuCl}_{4}(0.2 \mathrm{mM}, 10 \mathrm{ml})$ was titrated via a syringe pump at a rate of $0.8 \mathrm{~mL} / \mathrm{min}$ into $0.5 \mathrm{~mL}$ of synthesized silver nanocube until the color of the reaction was stable. Because of the reaction stoichiometry for the galvanic replacement reaction (i.e., oxidation of three $\mathrm{Ag}$ atoms produces one gold atom), hollow structures are produced.

\section{Synthesis of hollow gold nanostars (HGNSs)}

The hollow gold nanostars (HGNSs) were synthesized via a seed-mediated growth method (Wang 2012). First, silver seed nanoparticles were synthesized as sacrificial templates which provides rough surface and active sites for the further deposition of gold nanoparticles. Briefly $\mathrm{AgNO}_{3}$ was dissolved in $25 \mathrm{~mL}$ of deionized water and preheated at $80{ }^{\circ} \mathrm{C}$. Then sodium citrate $(1 \%$ in mass, $1.5 \mathrm{~mL})$ added to initiate the reduction of $\mathrm{AgNO}_{3}$ and the temperature was increased to $110{ }^{\circ} \mathrm{C}$. Next, for synthesis of HGNSs, $\mathrm{HAuCl}_{4}$ aqueous solution $(1 \mathrm{~mL}, 2.94 \mathrm{mM})$ and $\mathrm{AA}(10 \mathrm{mM}, 1 \mathrm{ml})$ slowly injected. The procedure was complete by galvanic replacement reaction between silver nanoparticles and $\mathrm{HAuCl}_{4}$.

\section{Coating GNSs with ABC triblock copolymer (GNSs@Pol)}

For preparation of both HGNSs and GNCs-coated polymers, each PVP-covered GNSs was separately dissolved in $2 \mathrm{~mL}$ of DI water. Then, a $10-\mathrm{mL}$ aqueous solution of PAAb-PNIPAAm-b-PCL-SH copolymer $(0.20 \mathrm{~g})$ to each of them and the mixture was shaken at $600 \mathrm{rpm}$ for 5 days. PVP was exchanged by PAA-b-PNIPAAm-b-PCL-SH copolymer. The solution was then centrifuged $\left(11,000 \mathrm{rpm}, 4{ }^{\circ} \mathrm{C}, 10 \mathrm{~min}\right)$ and the supernatant was discarded. Finally, the polymer-covered GNSs were washed with DI water (Yavuz 2009).

\section{Photothermal heating setup}

The photothermal effect of the GNSs was evaluated by observing temperature increase as a function of time. After exposing the GNSs to NIR continuous laser (808 $\mathrm{nm}$ wavelength diode laser, $2.5 \mathrm{~W}$, model: PSU-III-LED, Changchun new institute, China), the temperature rise was recorded. For evaluation of PTT, aqueous solutions of GNSs@Pol were diluted to a desired final concentration $\left(100 \mu \mathrm{g} \mathrm{mL}^{-1}\right)$ in phosphate-buffered saline 
(PBS; Sigma-Aldrich). Then, a certain amount of different aqueous suspension $(100 \mu \mathrm{l})$ was placed in a single well of a 96-well plate and irradiated with $808 \mathrm{~nm}$ continuouswave NIR laser at a power density of $0.7 \mathrm{~W} / \mathrm{cm}^{2}$ for exposure times of $2,4,6,8$ and $10 \mathrm{~min}$. The temperature of the suspensions was evaluated during irradiation by a digital thermocouple (LCD K-Type Digital Thermometer, Model: TM-902C w Thermocouple Wire, ShenZhen, China) immersed into suspensions.

\section{Dox-loading and release studies}

\section{Dox-loading on GNSs@Pol}

To load Dox into GNSs, $10 \mu \mathrm{L}$ aqueous solutions of Dox. $\mathrm{HCl}\left(2000 \mu \mathrm{g} \mathrm{mL} \mathrm{L}^{-1}\right)$ were added directly to the polymer-covered GNSs (GNSs@Pol; $1 \mathrm{~mL}, 200 \mu \mathrm{g} \mathrm{L}{ }^{-1}$ ). The mixture was stirred at room temperature for about $48 \mathrm{~h}$ under the dark situation. The unloaded Dox was removed by centrifugation $\left(11,000 \mathrm{rpm}, 4{ }^{\circ} \mathrm{C}, 10 \mathrm{~min}\right)$ and washing with DI water twice. The obtained product was denoted as GNSs@Dox-Pol. The loading efficiency of Dox was quantified using UV-vis spectroscopy (Jang 2014):

$$
\text { Doxencapsulationefficiency }\left(\% \frac{\mathrm{w}}{\mathrm{w}}\right)=\frac{\text { amountofDoxinnanoparticle }}{\text { amountoffeededDox }} .
$$

\section{Effect of $p H$ on the Dox release from GNSs@Dox-Pol}

In order to evaluate pH-responsive Dox release from GNSs@Dox-Pol, $1 \mathrm{~mL}$ of each GNSs@ Dox-Pol suspensions were dispersed in $1 \mathrm{~mL}$ of PBS solution with three different $\mathrm{pH}$ values $(4,5.4$, and 7.4$)$ and shaken in an incubator at $37{ }^{\circ} \mathrm{C}$ for definite times. At distinct time intervals, GNSs@ Dox-Pol were collected by centrifugation (11,000 rpm, for $10 \mathrm{~min}$ ) for recognition of released Dox. After that, equal amount of fresh medium of PBS solutions were added to resuspend the GNSs@ Dox-Pol microtube. Released drugs were measured from the supernatant at $480 \mathrm{~nm}$ using an ultraviolet-visible spectral measurement by the following formulae:

$$
\text { Drugrelease }(\% 100)=\frac{\text { amountofDoxreleaseinamedium }}{\text { amountofDoxloadedinnanoparticles }} \times 100 .
$$

\section{Effect of laser irradiation on the release of Dox from GNSs@ Dox-Pol}

For each data point, $1 \mathrm{~mL}$ of each GNSs@Dox-Pol transferred to a 1-mL centrifuge tube. Before laser irradiation, the samples were shaken and preheated in an incubator to $37^{\circ} \mathrm{C}$. Then each sample was separately irradiated by a $808 \mathrm{~nm}$ laser for $10 \mathrm{~min}(0.7 \mathrm{~W} /$ $\mathrm{cm}^{2}$ ) at defined time intervals. After exposure, samples were collected by centrifugation (11,000 rpm for $10 \mathrm{~min})$. The percentage of released Dox in the supernatant was determined by an ultraviolet-visible spectral measurement at $480 \mathrm{~nm}$ (Eq. 2).

\section{Hemolytic activity test}

To evaluate, the biocompatibility of GNSs@Pol, hemolytic activity test (red blood cells, RBCs) was performed according to the recent literature (Zhou 2015). For this purpose, human fresh blood samples were (taken from Iranian Blood Transfusion Institute (IBTI)) diluted with PBS and centrifuged (2500 rpm for 8 min, using an EDTA tube for 
stabilized RBCs) (Rahimi 2017). After removing the supernatant, RBCs were collected and washed several times with PBS (pH 7.4). The dilution of collected RBCs were then performed with PBS, from which $0.5 \mathrm{~mL}$ was added to $0.5 \mathrm{~mL}$ PBS (as negative control), and to $0.5 \mathrm{~mL}$ DI water (as positive control). The same amount of diluted RBCs suspension was then added to GNSs@Pol suspension with different concentrations (1.5, 3, $6.5,12.5,25,50$ and $100 \mu \mathrm{g} \mathrm{mL}{ }^{-1}$ ). After $3 \mathrm{~h}$ of incubation and shaking (at $37^{\circ} \mathrm{C}$ ), samples were investigated under an optical microscope using a magnification of $\times 100$ for hemocompatibility. Finally, samples were centrifuged (5000 rpm for $5 \mathrm{~min}$ ) and released hemoglobin absorption at $540 \mathrm{~nm}$ was then analyzed for the supernatants (the experiment was repeated two more times) (Rahimi et al. 2017).

Hemolysis rate of samples were measured using the following formula:

$$
\text { Hemolysis }(\%)=\frac{(\text { Abs }- \text { Ab0 })}{(\text { Abs100 }- \text { Abs0 })} \times 100 \%,
$$

where Abs, Abs0, and Abs100 are the supernatant absorbance of samples, negative, and positive control, respectively.

\section{Cellular uptake studies}

\section{Cellular uptake assessment by flow cytometry and fluorescence microscope}

For quantitative evaluation of cellular uptake of bare GNSs and GNSs@Dox-Pol nanostructures, we have used flow cytometry method according to a previous report (Poursalehi 2019). For this purpose, rhodamine B-loaded GNSs and GNSs@Dox-Pol nanostructures were treated with MCF-7 cells. After 1 and $3 \mathrm{~h}$, the cells were trypsinized and washed with PBS and counted with a FACScalibur flow cytometer (Becton Dickinson Immunocytometry Systems, San Jose, CA, USA) to measure fluorescent intensity. For further confirmation of cellular uptake of samples, fluorescence microscope (Olympus microscope Bh2-RFCA, Japan) images were captured for qualitative assessment.

\section{In vitro cell uptake assay by ICP-MS}

The intracellular content of GNSs was further evaluated using inductively coupled plasma mass spectrometry (ICP-MS) (Dykman and Khlebtsov 2012). Approximately 100,000 cells were seeded into a 12-well plate in complete RPMI 1640 media and incubated at $37{ }^{\circ} \mathrm{C}$ for $24 \mathrm{~h}$. After reaching $~ 80 \%$ confluency, MCF-7cells were treated with samples (GNCs, GNCs@Dox-Pol, HGNSs, and HGNSs@Dox-Pol) in FBS-free RPMI 1640 for $3 \mathrm{~h}$. After $3 \mathrm{~h}$, the cells were extensively washed with ice-cold PBS four times to remove any nanoparticles that were still bound to the cell surface. Studies showed that four wash cycles were sufficient to remove essentially all GNSs bound to the cell surface, leaving only the internalized GNSs (Hou 2016). MCF-7 cells were trypsinized and washed with freshly aqua regia $(1 \mathrm{~mL})$ to completely digest the cells and dissolve the gold nanostructures. The resulting solution was incubated at room temperature for $24 \mathrm{~h}$ and then heated to remove aqua regia. To determine gold content by ICP-MS (PerkinElmer, Waltham, MA, USA) residual was dissolved in DI water. 


\section{Cell viability assay}

\section{Cell viability assay before photothermal treatment}

For in vitro cytotoxicity studies, breast adenocarcinoma (MCF-7) cells were seeded in 96-well plates $(1 \times 104$ cells/well $)$ in RPMI 1640 supplemented with $10 \%$ FBS and $1 \%$ benzylpenicillin/streptomycin and incubated at $37{ }^{\circ} \mathrm{C}$ in $5 \% \mathrm{CO}_{2}$ overnight. Dox, HGNSs, HGNSs@Pol, HGNSs@Dox-Pol, GNCs, GNCs@Pol, and GNCs@Dox-Pol with different concentrations $\left(1.5,3,6.5,12.5,25,50\right.$ and $\left.100 \mu \mathrm{g} \mathrm{mL}^{-1}\right)$ were diluted with complete RPMI 1640 medium and added to MCF-7 cells and further incubated for $48 \mathrm{~h}$. After that cell media were removed carefully and MTT solution in cell growth culture ( $200 \mu \mathrm{L}, 5 \mu \mathrm{g} \mathrm{mL} \mathrm{m}^{-1}$ ) was added to each well and incubated for $4 \mathrm{~h}$ at $37^{\circ} \mathrm{C}$. Cells without treatment were regarded as negative controls. The optical density of the medium was measured using an ELISA plate reader (Awareness Technology, Palm City, FL, USA) at $\lambda=595 \mathrm{~nm}$.

\section{Cell viability assay after photothermal treatment}

To estimate the effectiveness of PTT, MCF-7 cells were treated with $100 \mu \mathrm{g} \mathrm{mL}$ of GNSs@Pol, and the GNSs@Dox-Pol nanostructures. After 4 h, the medium was removed carefully and washed with PBS to eliminate un-uptaken GNSs. Culture medium was added again and the cells were irradiated (with NIR laser, $808 \mathrm{~nm}, 0.7 \mathrm{~W}$ for $10 \mathrm{~min}$; which from now on will be called irradiation for brevity). The cells that were exposed to only laser irradiation were considered as positive controls. Cells without treatment were regarded as negative controls. Cell viability was assessed by MTT assay method as described above.

\section{Cell cycling}

The effect of GNSs on the cell cycle in different phases is determined with reagents including DNA dyes such as propidium iodide (PI). MCF-7 cells were seeded in the 6 -well plate $\left(50 \times 10^{4}\right.$ cells/well $)$ and incubated for $24 \mathrm{~h}$. Then, the cells were treated with the $\mathrm{IC}_{50}$ concentration of samples (GNCs, GNCs@Dox-Pol, HGNSs, HGNSs@ Dox-Pol, and free Dox). After $4 \mathrm{~h}$, the medium was removed carefully and washed with PBS to eliminate un-uptaken GNSs. Culture medium was added again and incubated for $24 \mathrm{~h}$. Then, cells were irradiated and were further incubated for $3 \mathrm{~h}$. After that, cells were washed with PBS, trypsinized, harvested, and fixed with $1 \mathrm{~mL}$ of icecold $70 \%$ ethanol. The ethanol was discarded by centrifugation and cells were washed with PBS. The cell pellets were stained with the PI solution and RNaseA and incubated for $30 \mathrm{~min}$ at room temperature. The stained cells in different cell cycle phases were analyzed by FACSCalibur (Becton Dickinson).

\section{Apoptosis detection by DAPI staining}

DAPI staining is used for observing condensed and fragmented nuclei of the cells for qualitative study of apoptosis (Nam 2013; Kang 2015). For DAPI staining, MCF-7 cells were seeded in a 6-well plate $\left(5 \times 10^{4}\right.$ cells/well $)$ and incubated at $37{ }^{\circ} \mathrm{C}$ in $5 \% \mathrm{CO}_{2}$ overnight. Cells were then treated with $\mathrm{IC}_{50}$ concentration of samples (GNCs, GNCs@DoxPol, HGNSs, HGNSs@Dox-Pol, and free Dox). After $4 \mathrm{~h}$, the medium was removed carefully and washed with PBS to eliminate un-uptaken GNSs. Culture medium was 
added again and further incubated for $24 \mathrm{~h}$. Then, cells were irradiated and incubated for $3 \mathrm{~h}$. Subsequently, cells were implemented to fixation by $10 \%$ paraformaldehyde. After washing with PBS, Triton X-100 (0.1\% w/v) was added for $15 \mathrm{~min}$ to increase the permeability of the cell membrane. Identification of apoptotic morphological alteration and DNA fragmentation of cells were investigated by staining the cells nuclei with DAPI under a fluorescence microscope (Olympus microscope Bh2-RFCA, Japan).

\section{Apoptosis detection by flowcytometric method}

To determine apoptotic cell's value, cells were seeded in six-well plates with a density of $5 \times 10^{5}$ cells per well in the culture medium and incubated for $24 \mathrm{~h}$. Then, the cells were treated with the IC50 concentration of samples (GNCs-Pol, GNCs@Dox-Pol, HGNSsPol, HGNSs@Dox-Pol). After $4 \mathrm{~h}$, the medium was removed carefully and washed with PBS to eliminate un-uptaken GNSs. Culture medium was added again and incubated for $24 \mathrm{~h}$. Then, cells were irradiated and were further incubated for $3 \mathrm{~h}$. Non-treated cells were considered as control. After $24 \mathrm{~h}$, the cells were trypsinized, collected, and finally, they centrifuged and dispersed in $1 \mathrm{ml}$ PBS. The cells were suspended in $100 \mu \mathrm{L}$ annexinbinding buffer and $2.5 \mu \mathrm{l}$ Annexin-V and $2.5 \mu \mathrm{L}$ propidium iodide (PI)was added to cell suspension for $14 \mathrm{~min}$ and kept in dark at room temperature (according to ex-bio kit manufacture protocol). Finally, a FACS Calibur flow cytometer was used for the percentage of early and late apoptosis Annexin-V/PI apoptosis assay.

\section{Results and discussion}

\section{Characterization of gold nanostructures and micelles}

The UV-Vis spectra verified the evolution process of both GNSs (Fig. 1). By optimizing the experimental conditions, the SPR peak of HGNSs and GNCs were tuned in the NIR region (Fig. 1a). UV-Vis spectra of Ag colloid that was used as seed nanoparticles for the synthesis of HGNSs showed an SPR peak in $468 \mathrm{~nm}$. This peak shifted to the red region $(820 \mathrm{~nm})$ by adding AuCl4- (the sign of HGNSs formation). Coating of HGNSs with polymer shifted the peak to $848 \mathrm{~nm}$ (owing to light scattering of a polymeric shell). UV-Vis spectra of Ag nanocubes showed an SPR peak in $416 \mathrm{~nm}$. For the synthesis of GNCs, galvanic replacement of $\mathrm{Au} / \mathrm{Ag}$ ions was carried out which lead to a redshift in SPR peak $(782 \mathrm{~nm})$. Similarly, coating of GNCs with polymer also shifted the UV-Vis spectra peak to $856 \mathrm{~nm}$ (Fig. 1b).

TEM images of free micelles and micelle-coated GNSs are shown in Fig. 2. The average particle size of free micelles was around $50 \mathrm{~nm}$. For GNCs, and HGNSs, the size in wall length were $40-50$ and $20-25 \mathrm{~nm}$, respectively (interior pore size for GNCs and HGNSs were $2-4 \mathrm{~nm}$ and $1-2 \mathrm{~nm}$, respectively). After encapsulation by copolymer, a light shell appeared around the GNSs as can be seen in Fig. 2d, g.

Particle size, surface charge, and polydispersity index (PDI) of the GNSs and GNSs@ Pol are shown in Table 1 and Fig. 3. The surface charge of GNSs was different in each stage which was verified by zeta potential ( $)$. Since the surface of GNCs and HGNSs were covered with PVP and citrate, $\zeta$ potential of GNCs and HGNSs were neutral and negative, respectively $(1.4$ and $-10 \mathrm{mV})$. Coating of GNCs and HGNSs with polymer caused a decrease in zeta potential to -28.8 and $-24 \mathrm{mV}$, respectively. For nanoparticles, zeta potential value could determine their stability (higher positive or negative zeta 


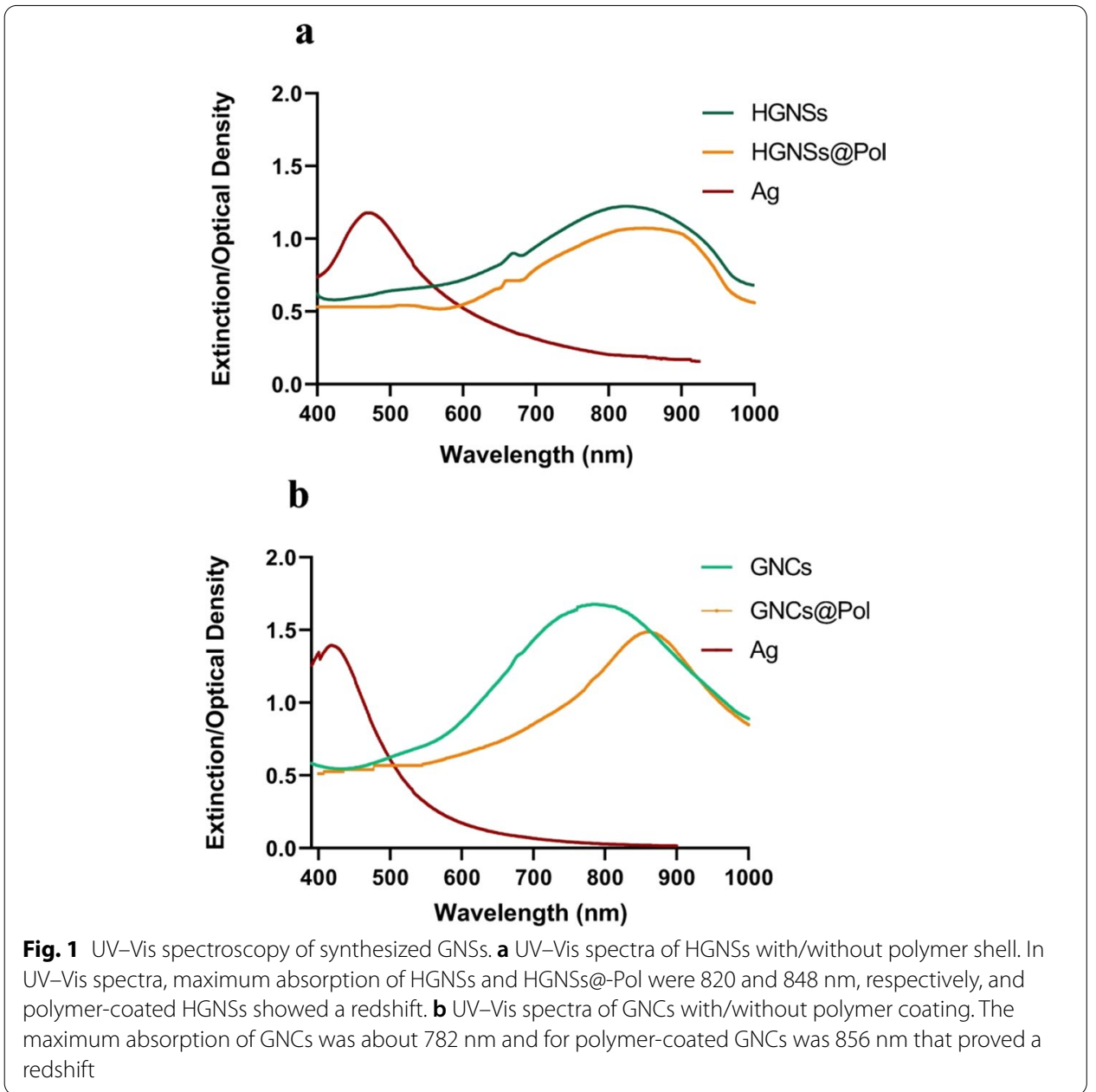

potential indicates higher stability) (Honary and Zahir 2013; Jalilzadeh 2020). PDI confirmed the narrow distribution of the GNSs and GNSs@Pol.

Figure 4a shows the stability of GNSs and GNSs@Pol in serum-containing buffer solution after 2 months of keeping at $4{ }^{\circ} \mathrm{C}$. The solution of HGNSs@Pol was found to be monodisperse after 2 months without any visible aggregation proved by particle size $(128.8 \mathrm{~nm})$ and PDI (0.139) captured by DLS (Table 2). Comparison of SPR peak of HGNSs@Pol right after synthesis and after 2 months of maintenance at $4{ }^{\circ} \mathrm{C}$ showed no observable change which approved its stability. However, GNCs@Pol particle size showed $65 \mathrm{~nm}$ increase after 2 months (Table 2). Moreover, the SPR peak of GNCs@Pol became wider after 2 months which shows a lesser stability for GNCs@Pol compared to HGNSs@Pol.

\section{In vitro photothermal conversion comparison}

Previous studies discovered that due to the excellent tissue penetration capability of NIR laser, $808 \mathrm{~nm}$ laser was selected for the photothermal study. To receive enough energy from every particle inside the cells by $808 \mathrm{~nm}$ laser, the exposure time was increased (10 min) (Gharatape 2016; Seo 2018; Cabral and Baptista 2013). GNCs and HGNSs show special NIR optical property and can be used as photothermal agents 


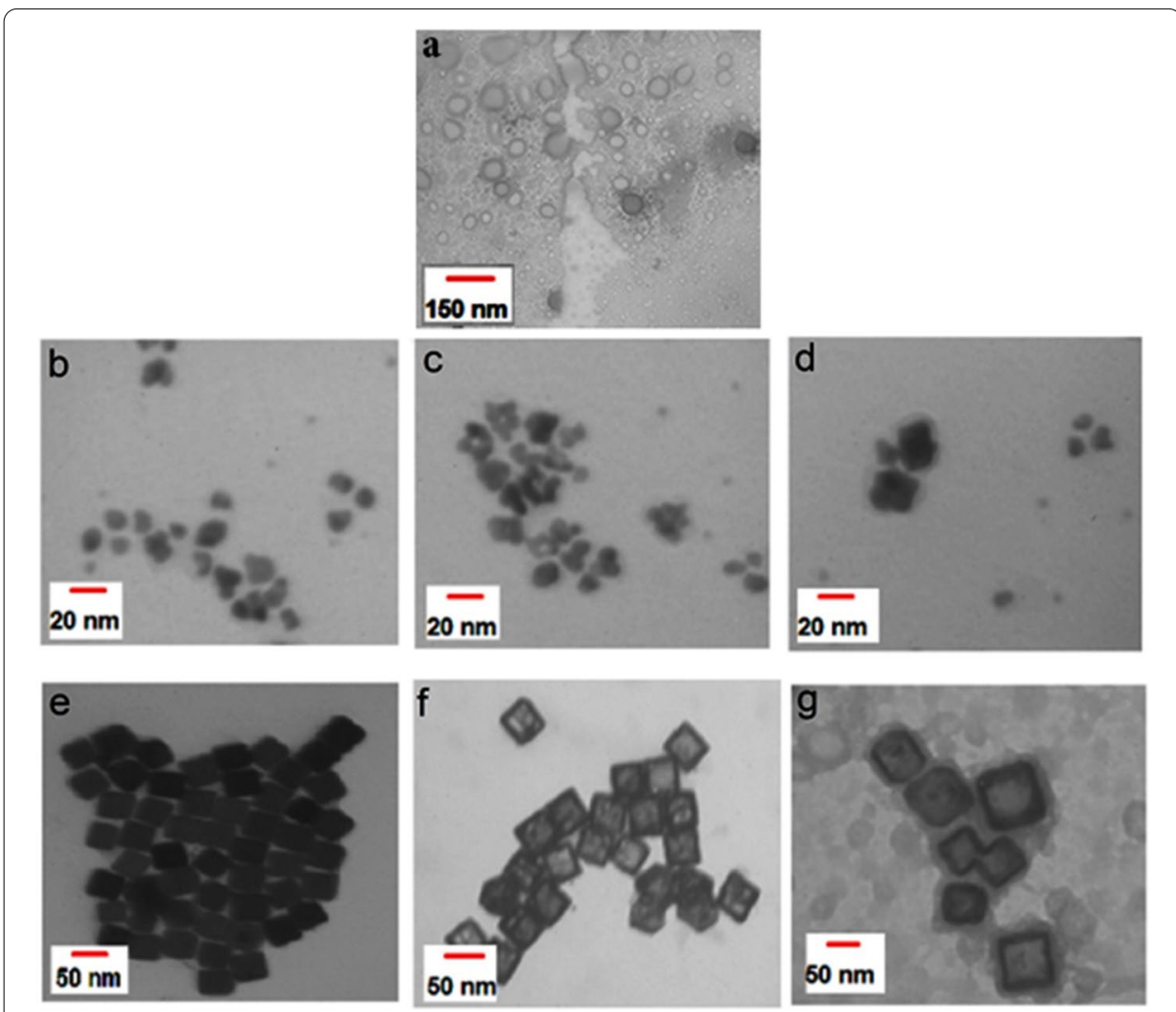

Fig. 2 TEM image of synthesized GNSs. a Free micelles with an average size of around $50 \mathrm{~nm}$. b-d Ag nanostars, HGNSs and HGNSs@Pol. e-g Ag nanocubes, GNCs and GNCs@Pol, respectively

Table 1 Size, PDI, and zeta potential of the synthesized nanostructures

\begin{tabular}{llll}
\hline GNSs & Size $(\mathbf{n m})$ & PDI & $\begin{array}{l}\text { Zeta } \\
\text { potential } \\
(\mathbf{m V})\end{array}$ \\
\hline HGNSs & 22.39 & 0.493 & -10 \\
HGNSs@Pol & 132 & 0.478 & -24 \\
GNCs & 88.31 & 0.139 & 1.4 \\
GNCs@Pol & 238.8 & 0.344 & -28.5 \\
\hline
\end{tabular}

(Wang 2012; Khan 2012). In our experiments, their photothermal conversion property was investigated via laser irradiation at $\lambda=808 \mathrm{~nm}$ at a power density of $0.7 \mathrm{~W}$ $\mathrm{cm}^{-2}$ in various exposure times with $100 \mu \mathrm{g} \mathrm{mL}^{-1}$ concentration of GNSs. Temperature increase $(\Delta T)$ of GNCs and HGNSs suspension after 1 min laser irradiation was 12 and $13{ }^{\circ} \mathrm{C}$, respectively (Fig. 5). As expected, after $10 \mathrm{~min}$, temperature rise $(\Delta T)$ for GNCs showed 25 increase and for HGNSs showed $27.5^{\circ} \mathrm{C}$ increase, whereas the temperature of pure water only showed $3{ }^{\circ} \mathrm{C}$ increase under similar conditions. The obtained results showed that after exposure of GNSs solution to laser irradiation for 10 min, $\Delta T$ of HGNSs was higher than GNCs. Hence, both these structures have the potential for photothermal conversion, and HGNSs proved to have a slightly higher 
(a)

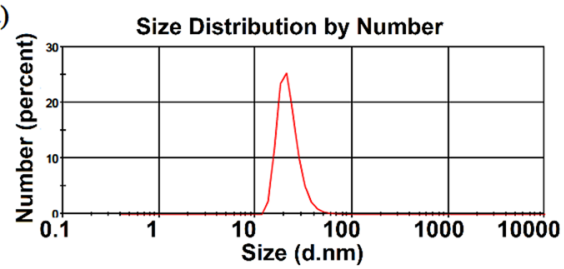

(c)

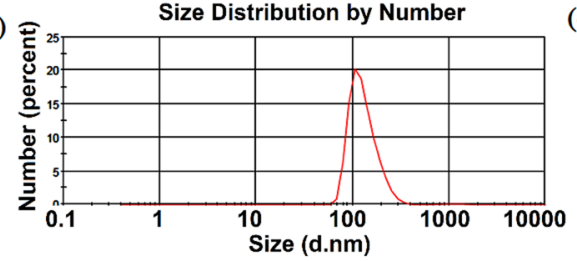

(e)

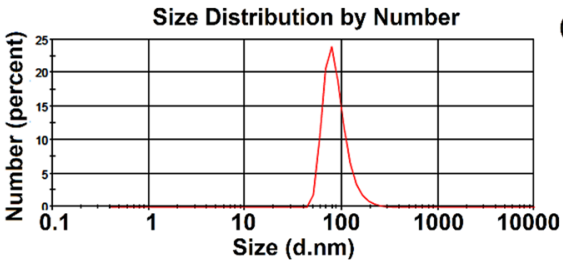

(g)

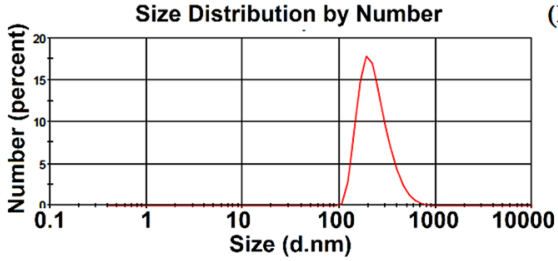

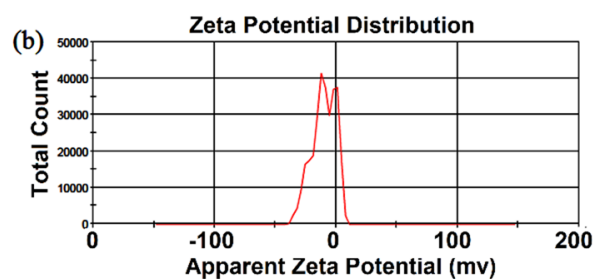

(d)

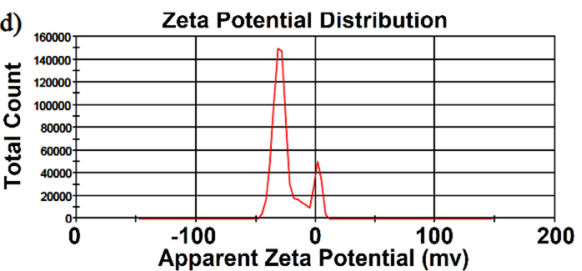

Zeta Potential Distribution

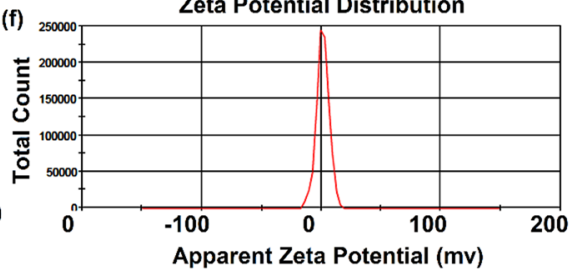

(h)

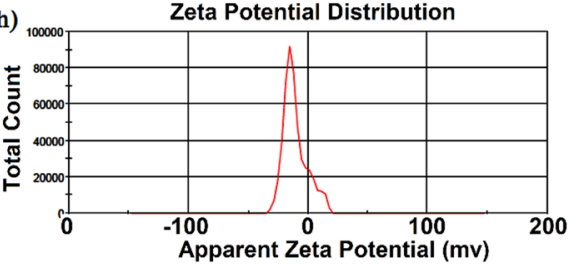

Fig. 3 a Particle size of HGNSs, b zeta potential of HGNSs, c particle size of HGNSs@Pol, d zeta potential of HGNSs@Pol, e particle size of GNCs, $\mathbf{f}$ zeta potential of GNCs, $\mathbf{g}$ particle size of GNCs@Pol and $\mathbf{h}$ zeta potential of GNCs@Pol obtained by DLS

potential. This is likely due to the presence of multiple sharp spikes in HGNSs, which act like lightning rods that dramatically enhance the local electromagnetic field (Liu 2015). Therefore, we observe that the photothermal conversion efficiency depends on the shape and morphology of the gold nanoparticles. This is in accordance with the Wang et al. study which reported a higher temperature boost in gold nanocages compared to gold nanospheres (Wang 2015). Likewise, Moustaoui et al. compared the temperature rise of spherical and urchin-shaped gold nanoparticles and demonstrated that branched nanoparticles display a higher temperature elevation than spherical shaped nanoparticles Moustaoui 2019).

\section{Biocompatibility of polymer-coated GNSs}

Hemolysis assay was applied to determine the biocompatibility of nanoparticles. Minimal hemolysis after nanoparticles interaction with red blood cells (RBCs) is a sign of their biocompatibility (Rahimi et al. 2017). Since HGNSs have better PTT ability, they were chosen for hemolysis assay to estimate the blood adaptability of HGNSscoated ABC triblock copolymer (HGNSs@Pol) on RBCs (Fig. 6a,b). In this concern, RBCs were treated with various concentrations of HGNSs@Pol $\left(1.5-100 \mu \mathrm{g} \mathrm{mL} \mathrm{L}^{-1}\right)$ as well as PBS buffer ( $\mathrm{pH} 7.4)$, and deionized water as the negative and positive control, 
a
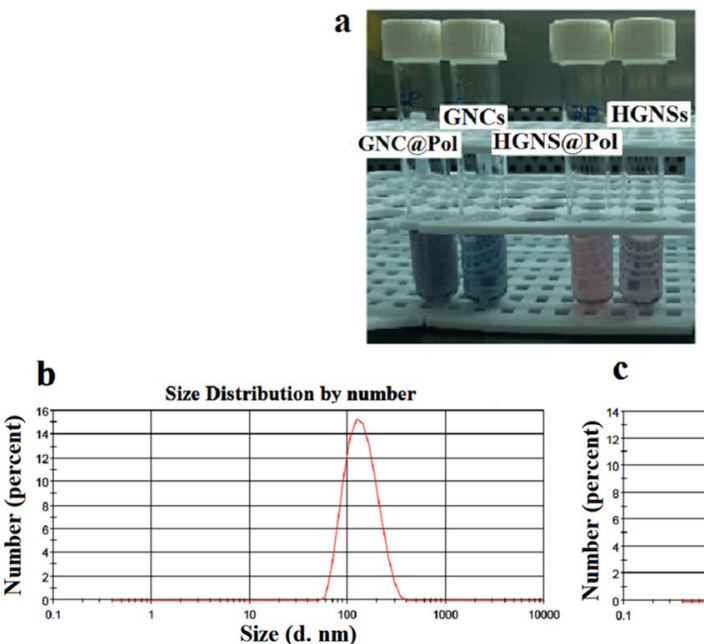

c
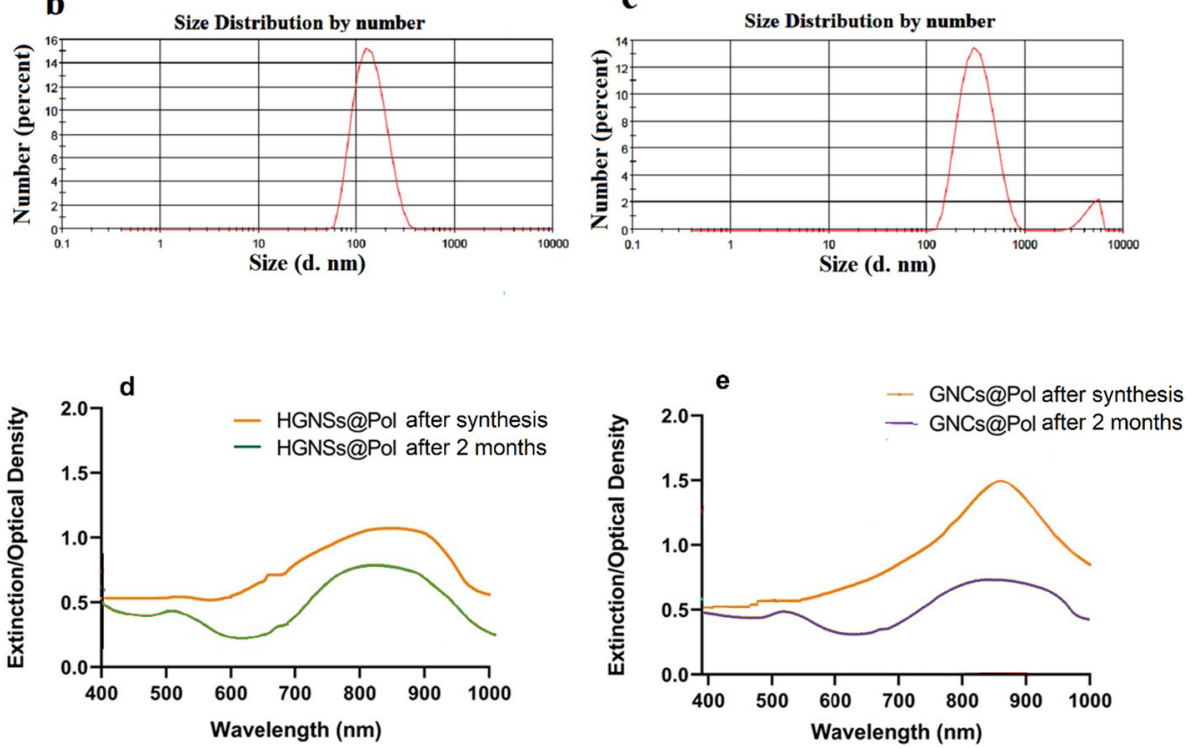

Fig.4 a Image of GNCs@Pol, GNCs, HGNSs@Pol, and HGNSs suspended in serum-containing buffer solution after 2 months at $4{ }^{\circ} \mathrm{C}$ (pH 7.4); particle size of $\mathbf{b}$ HGNSs@Pol and $\mathbf{c}$ GNCs@Pol after 2 months; Comparison of SPR peak right after synthesis and after 2 months of keeping in $4{ }^{\circ} \mathrm{C}$ for $\mathbf{d}$ HGNSs@Pol and e GNCs@Pol.

Table 2 Particle size and PDI of the HGNSs@Pol and GNCs@Pol after 2 months

\begin{tabular}{lll}
\hline GNSs & Size $(\mathbf{n m})$ & PDI \\
\hline HGNSs@Pol & 128.8 & 0.139 \\
GNCs@Pol & 307.2 & 0.344 \\
\hline
\end{tabular}

respectively. Treatment of RBCs with PBS buffer did not modify the normal cells form, but deionized water-induced complete hemolysis of erythrocytes. The absorption of supernatant samples was measured at $540 \mathrm{~nm}$ (hemoglobin) by UV-Vis. The results showed that in physiological conditions, a high concentration of HGNSs@Pol $\left(100 \mu \mathrm{g} \mathrm{mL}^{-1}\right)$ did not have any hemolytic effect. But in $200 \mu \mathrm{g} \mathrm{mL} \mathrm{m}^{-1}$ which is the IC50 concentration of free micelles, a slight hemolytic effect was observed (Fig. 6a). Optical microscope imaging showed that RBCs shape do not have significant changes after treatment for $3 \mathrm{~h}$ and their disc-like structure has been preserved (Fig. 6b). Therefore, it can be concluded that HGNSs@Pol are suitable in drug delivery systems and other in vivo applications. 


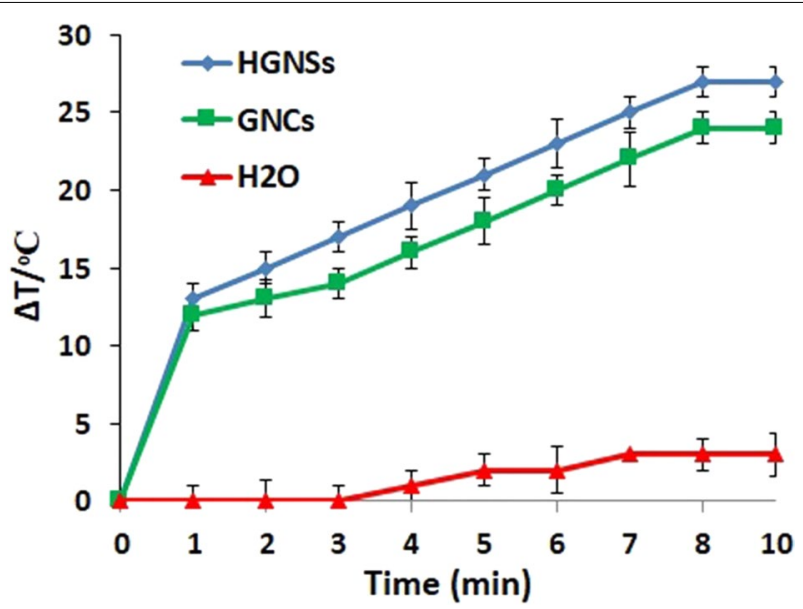

Fig. 5 The plots of time-dependent temperature increase $(\Delta T)$ for suspensions of HGNSs (blue) and GNCs (red) as a function of irradiation time using a $808 \mathrm{~nm}$ laser with a power density of $0.7 \mathrm{~W} \mathrm{~cm}{ }^{-2}$

\section{Loading and in vitro release of Dox}

The influences of pH and laser irradiation in the Dox release profile of GNSs@Pol were measured by UV-Vis spectroscopy similar to the method used in Liao (2015). According to the standard absorption curve of Dox $(\lambda \max =480 \mathrm{~nm})$, entrapped efficiency of Dox in HGNSs@Pol and GNCs@Pol were 78.02\% and 84.3\%, respectively.

\section{pH-responsive release of Dox from GNSs@Dox-Pol}

In order to investigate pH-responsive release profile, Dox release from HGNSs@Pol and GNCs@Pol was investigated at three different $\mathrm{pH}$ values (4, 5.4 and 7.4). At pH 4, over 58 and 55\% of Dox were released from the GNCs@Pol and HGNSs@Pol in 24 h, respectively. As shown in Fig. 7a, the drug released amounts in the pH 5.4 and 7.4 were 36 and 20\% for HGNSs@Pol and 40 and 23\% for GNCs@Pol in 24 h, respectively. After 6 days of incubation at pH 4, 77 and 71\% of Dox was released from GNCs@Pol and HGNSs@ Pol, respectively. At the same period of time at pH 5.4, 56 and 46\% of Dox was released from GNCs@Pol and HGNSs@Pol, respectively. At physiological pH (7.4) after 6 days only $30 \%$ of Dox was released from both formulations. Results showed that at all values of pH, Dox release values were higher for GNCs@Pol than for HGNSs@Pol. This could be explained by larger pore diameters and a higher number of pores in GNCs which makes the release of Dox easier (Sun 2017). pH-dependent Dox release behavior in both nano-formulations can be explained by the formation and elimination of ionic interaction between Dox and nanocarrier by variation of release medium $\mathrm{pH}$. Under physiological conditions ( $\mathrm{pH}: 7.4$ ), Dox release is limited due to the presence of ionic interaction between the protonated amine group of Dox $(\mathrm{pka}=8.3)$ and de-protonated carboxylic acid groups of PAA ( $\mathrm{pka}=5.6$ ). Whereas at $\mathrm{pH} \leq 5.4$ carboxylic acid groups of PAA are protonated $(\mathrm{Pka}=5.6)$ and ionic interaction between nanocarrier and Dox was removed, and hence Dox was released (Salehi et al. 2015). Abbasian et al. showed that Dox release from GNRs@Dox-Pol at pH 4, 5.4, and 7.4 after 150 h (at $37^{\circ} \mathrm{C}$ ) was 70, 50.8, and 22\%, respectively. They also showed that by increasing temperature to $45{ }^{\circ} \mathrm{C}$ Dox release 
(a)
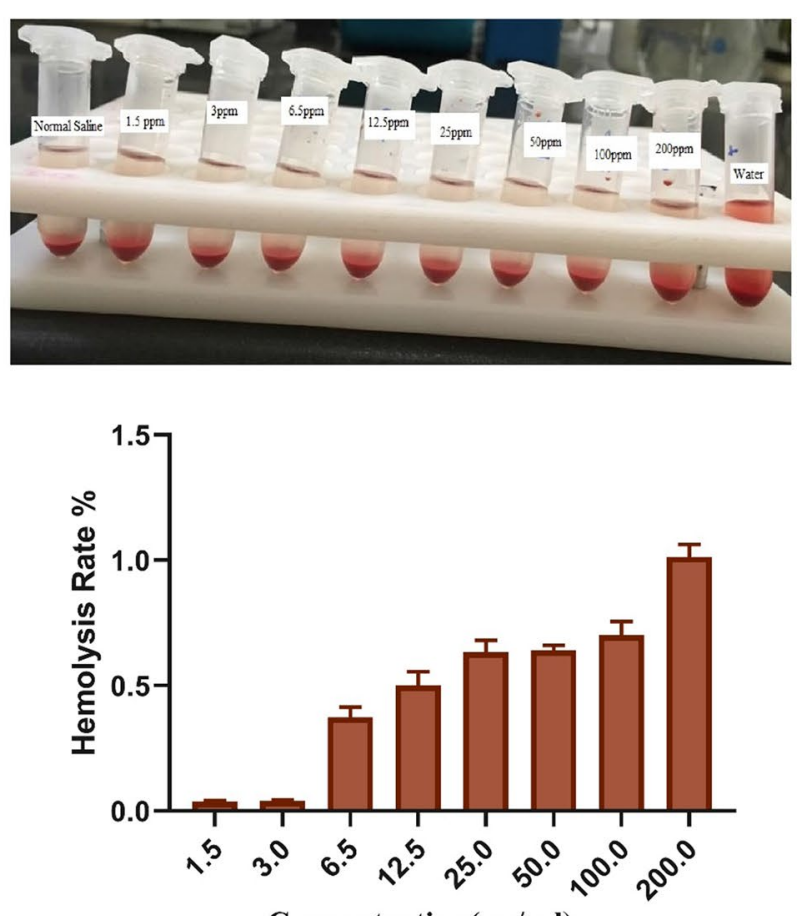

(b)

Concentration $(\mu \mathrm{g} / \mathrm{ml})$
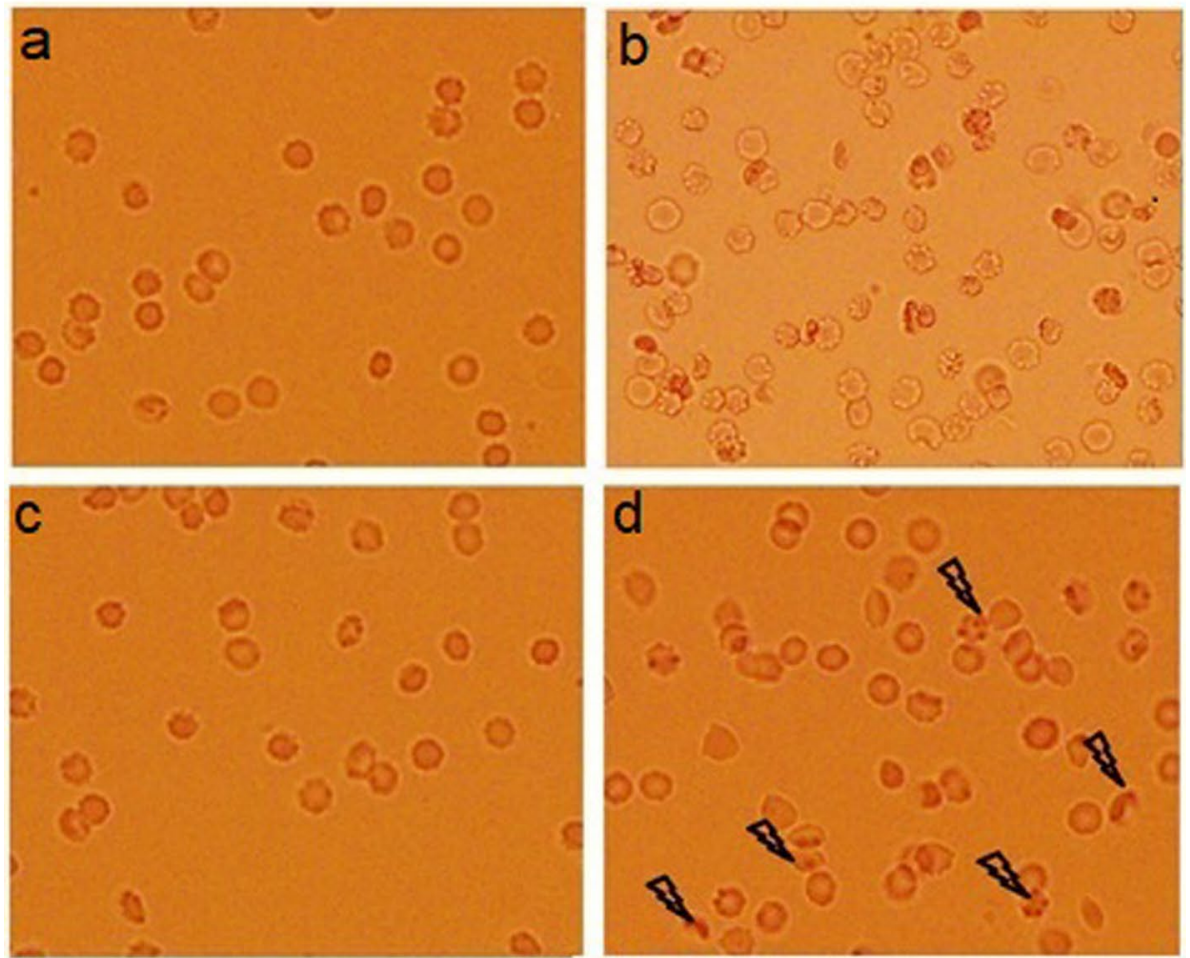

Fig. 6 a Hemolysis rate of HRBCs in different concentrations of $A B C$ triblock copolymer (1.5, 3, 6.5, 12.5, 25, 50,100 and $\left.200 \mathrm{\mu g} \mathrm{mL}^{-1}\right)$. b Representative images of the hemolytic test under light microscopy: a normal saline, $\mathbf{b}$ distilled water, $\mathbf{c} 100 \mu \mathrm{g} \mathrm{mL} \mathrm{L}^{-1}$, and $\mathbf{d} 200 \mu \mathrm{g} \mathrm{mL} \mathrm{L}^{-1}$ of HGNSs@Pol 

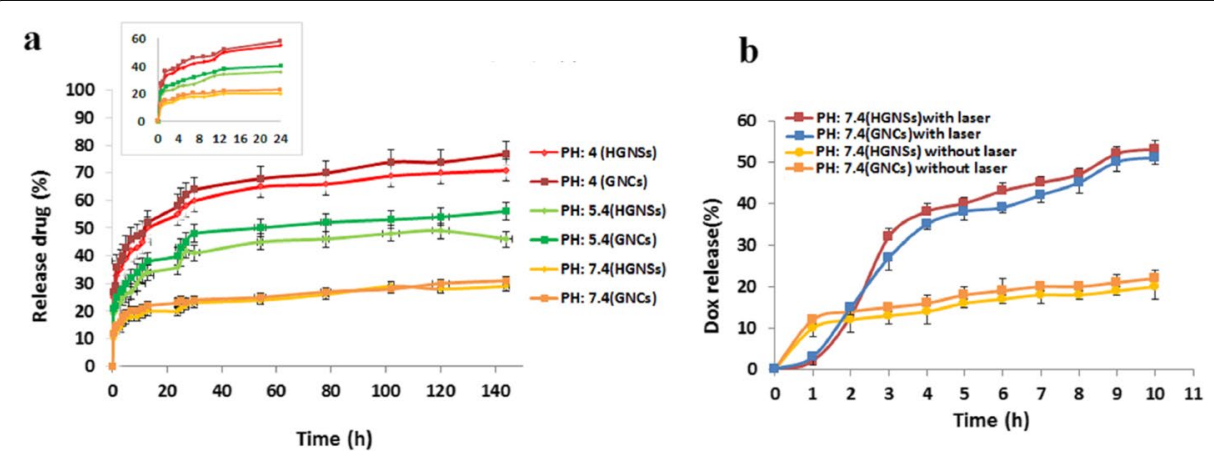

Fig. 7 a Profile of Dox release at three different $\mathrm{pH}$ values (4, 5.4 and 7.4). b Profile of Dox release with and without laser irradiation in normal physiological pH (7.4)

increased to 85,60 , and $31.65 \%$, respectively, at the same $\mathrm{pH}$ values and period of time (Abbasian 2017).

\section{Effect of laser irradiation on the Dox release from GNSs@ Dox-Pol}

Dox release from GNSs@Dox-Pol was significantly accelerated by laser irradiation that can be explained by temperature-sensitive properties of the copolymer (Xia 2011). The lower critical solution temperature (LCST) of the ABC copolymer was $41{ }^{\circ} \mathrm{C}$ (Abbasian 2017). In fact, at temperatures higher than LCST, PNIPAAm chains collapse, and hence opens the pores and leads to a release of the preloaded Dox. The heat needed for this process was provided by laser irradiation (Cobley 2010). As shown in Fig. 7b, over $55 \%$ of drug released happens in the first $10 \mathrm{~h}$ (released amounts would be increased in HGNSs due to better light to heat conversion). When the laser is turned off the polymer chains will relax back to the extended state, and thereby interrupting the release. Our results were in accordance with the study by Yavuz et al. that the release rate of Dox from GNCs coated with thermo-responsive polymers was accelerated by laser irradiation (Yavuz 2009; Li 2011).

\section{Intracellular uptake in vitro}

The physicochemical properties of nanostructures could influence cellular uptake (Jiang 2015; Lara-Cruz 2019; Dykman and Khlebtsov 2014). In PTT, the higher cell uptake of GNSs (as heat transducers), the higher chance of transduction of photon energy into heat. In vitro uptake of GNSs into MCF-7 cells was investigated by flow cytometry, fluorescent microscopy and ICP-MS. Flow cytometry provides a quantitative measure of cellular uptake of GNs@Dox-Pol and GNSs. The fluorescent intensity of rhodamine B corresponds to the internalized amounts of GNSs@Dox-Pol and GNSs. Although GNSs (GNCs and HGNSs) treatment group showed slight fluorescence intensity, coating with Dox-Pol (GNSs@Dox-Pol) significantly increased this intensity. This indicates that the copolymer coating, as the biocompatible outer layer, had a significant positive effect on cellular uptake of GNSs (Fig. 8a). This confirms the report by Sun et al. that the 4T1 cell membranes coated on the Dox-loaded gold nanocages can increase the uptake of cancer cells by enhancing the fluorescence intensity (Sun 2017). 

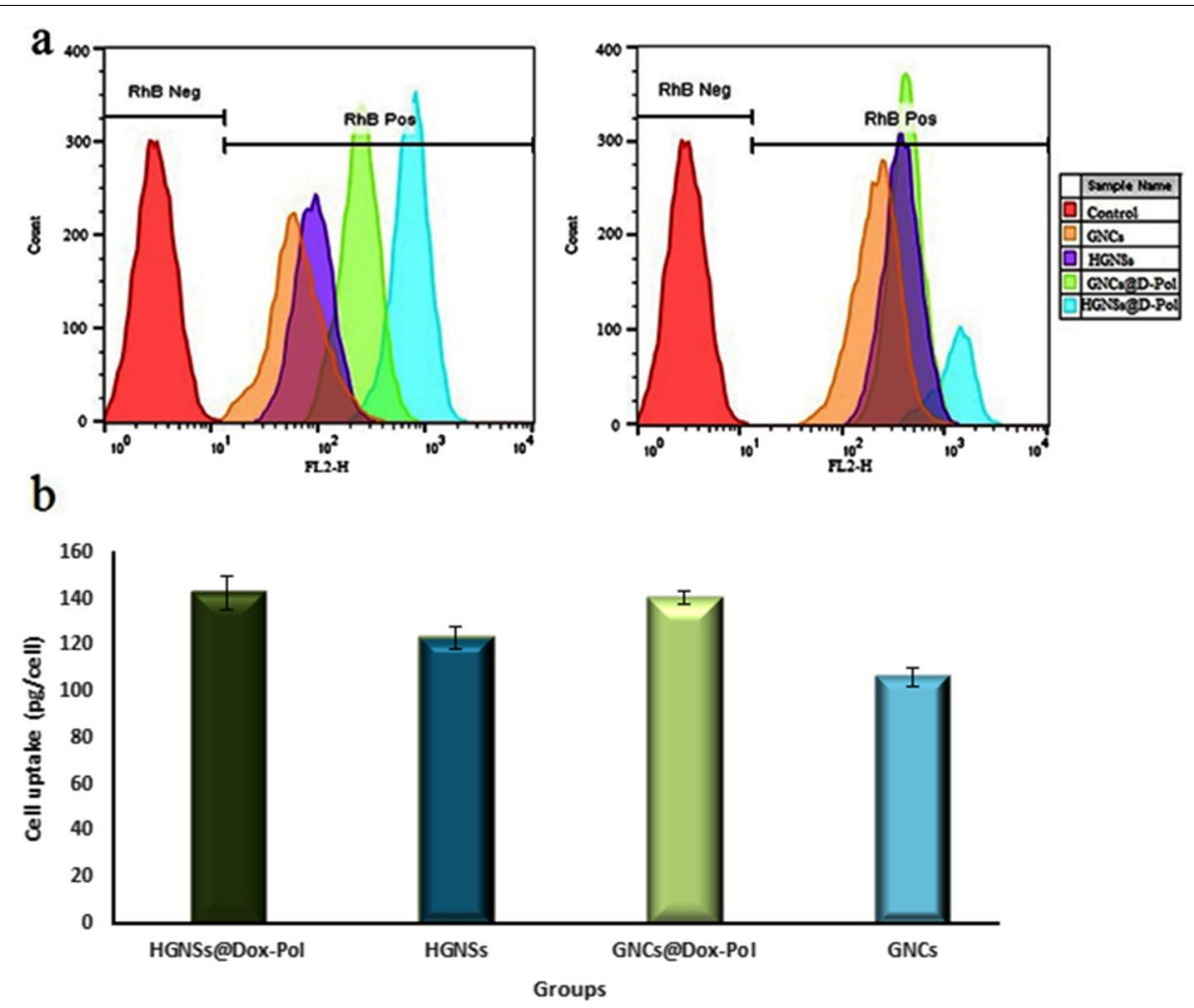

Fig. 8 Quantitative results of cell uptake assay of GNSs@Dox-Pol and GNSs measured by a flow cytometry and $\mathbf{b}$ by ICP-MS

Using ICP-MS, the intracellular Au content of samples was measured quantitatively. As shown in Fig. 8b, the cell uptake of HGNSs after $3 \mathrm{~h}$ of incubation, was higher than that of GNCs (124 and $107 \mathrm{pg} /$ cell, respectively) due to the small size of HGNSs compared to GNCs (refer to Table 1). Another reason is that the branched shape of HGNSs has a higher probability to enter the cell in comparison with the cube-like morphology of GNCs which is consistent with previous studies (Wang 2013). After $3 \mathrm{~h}$ of incubation, the cell uptake of HGNSs@Dox-Pol and GNCs@Dox-Pol was 142.85 and 140.84 pg/cell, respectively. These results indicated that the polymer coating on GNSs can increase the potential of cell internalization, maybe due to the biocompatible nature of copolymer. This result is in accordance with the Wang et al. study, which compared the cellular uptake of different shapes of $\mathrm{Au}$ nanostructures (nanorod, nanocage and nanohexapod) using the ICP-MS method. Their results revealed the impact of gold nanostructure morphology on their uptake by cells. Their results showed that the cellular uptake of $\mathrm{Au}$ nanohexapods was significantly higher than other morphologies of gold nanostructures (Wang 2013).

To further confirm cellular uptake of the nanostructures, qualitative uptake of GNSs and GNSs@Dox-Pol was monitored by fluorescence microscopy. The cells were treated with rhodamine B-loaded GNSs (GNCs and HGNSs) and GNSs@Dox-Pol (GNCs@DoxPol and HGNSs@Dox-Pol) for 1 and 3 h. Figure 9 shows that rhodamine B intensity was increased from 1 to $3 \mathrm{~h}$. This result demonstrated the time-dependent gathering of the nanostructures into the cells. More fluorescent intensity (cell uptake) was observed for 


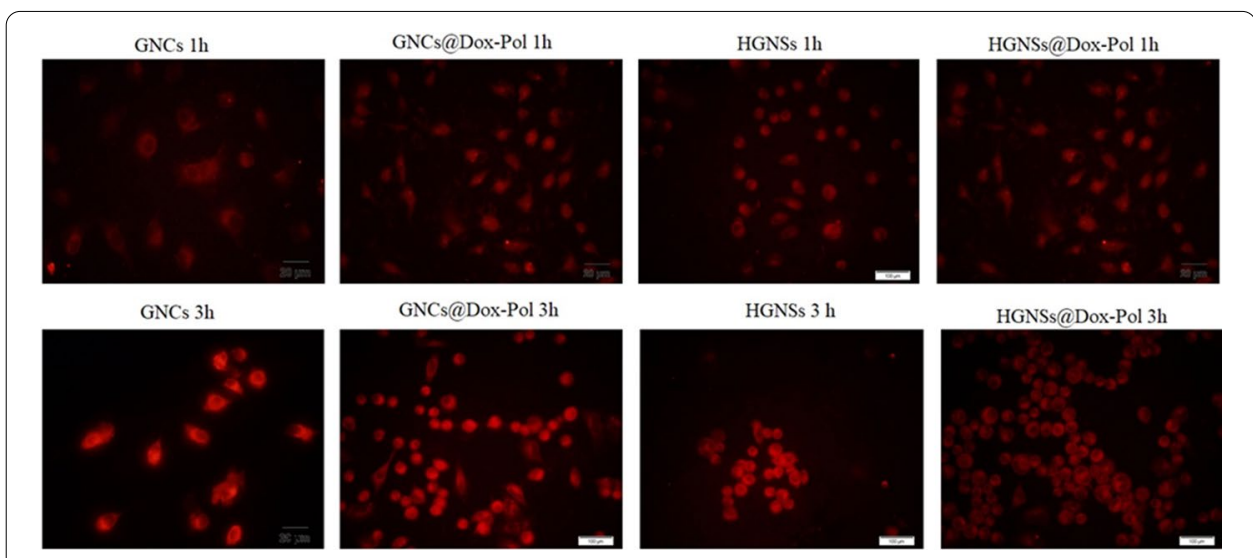

Fig. 9 Fluorescent microscopy images of Rhodamine B-labeled GNSs and GNSs@Dox-Pol uptake after 1 and $3 \mathrm{~h}$ of incubation in MCF-7 cancer cells

HGNSs and HGNSs@Dox-Pol in comparison with GNCs and GNCs@Dox-Pol, respectively, which can be explained by size-dependent cell uptake (Sonavane et al. 2008). Similar to results from flow cytometry and ICP-MS (Fig. 8), fluorescent microscopy results showed high fluorescent intensity for HGNSs@Dox-Pol and GNCs@Dox-Pol compared to HGNSs and GNCs. This can be explained by the biocompatibility of the copolymer. Liao et al. examined cellular uptake of the GNRs-loaded polymersomes with fluorescent microscopy and suggested that polymersomes can decrease the cytotoxicity of the GNRs and increase cell uptake efficiency (Liao 2015). The red color intensity was increased from 1 to $3 \mathrm{~h}$ indicating the time-dependent cell uptake of the nanoparticles into the cells. HGNSs@Dox-Pol had a stronger fluorescent intensity when compared with GNCs@Dox-Pol in cells which may be associated with small size (refer to Table 1) and branched morphology of HGNSs.

\section{Cytotoxicity assay}

The dose-dependent cytotoxicity of the bare GNCs and HGNSs toward MCF-7 cells was first evaluated by MTT assay (Broek 2011; Liao 2015). In vitro biocompatibility and cytotoxic effects of the ABC triblock copolymer, GNSs and GNSs@Pol were evaluated by MTT assay against MCF-7 cells for concentrations ranging from 1.5 to $100 \mu \mathrm{g} \mathrm{mL} \mathrm{m}^{-1}$ at the end of $48 \mathrm{~h}$ of the incubation period. As shown in Fig. 10, after $48 \mathrm{~h}$, the cell viability of copolymer was over $80 \%$, even at a high concentration of $100 \mu \mathrm{g} \mathrm{mL}{ }^{-1}$. This indicates that the synthesized copolymer was not toxic to MCF-7 cells. GNCs and HGNSs had an insignificant effect on MCF-7 cancer cells even at high concentrations (cell viability of GNSs was above $70 \%$ at $100 \mu \mathrm{g} \mathrm{mL}^{-1}$ ) which is in agreement with a report by Wang et al. (2014). After polymer coating (GNSs@ Pol) cell viability increased to a minimum of $90 \%$ in the same concentrations. Hence, coating of GNSs with copolymer increases its biocompatibility. Kumar Rengan et al. compared the biocompatibility of gold nanocages and hollow gold nanoshells under similar conditions (from 1.5 to $100 \mu \mathrm{g} \mathrm{mL}^{-1}$ ) in the L929 mouse fibroblast cell line. They found that the cell viability of the gold nanocages was above $90 \%$ at $100 \mu \mathrm{g} \mathrm{mL}^{-1}$ concentration. For gold nanoshells, they showed that, at the same concentration, the 

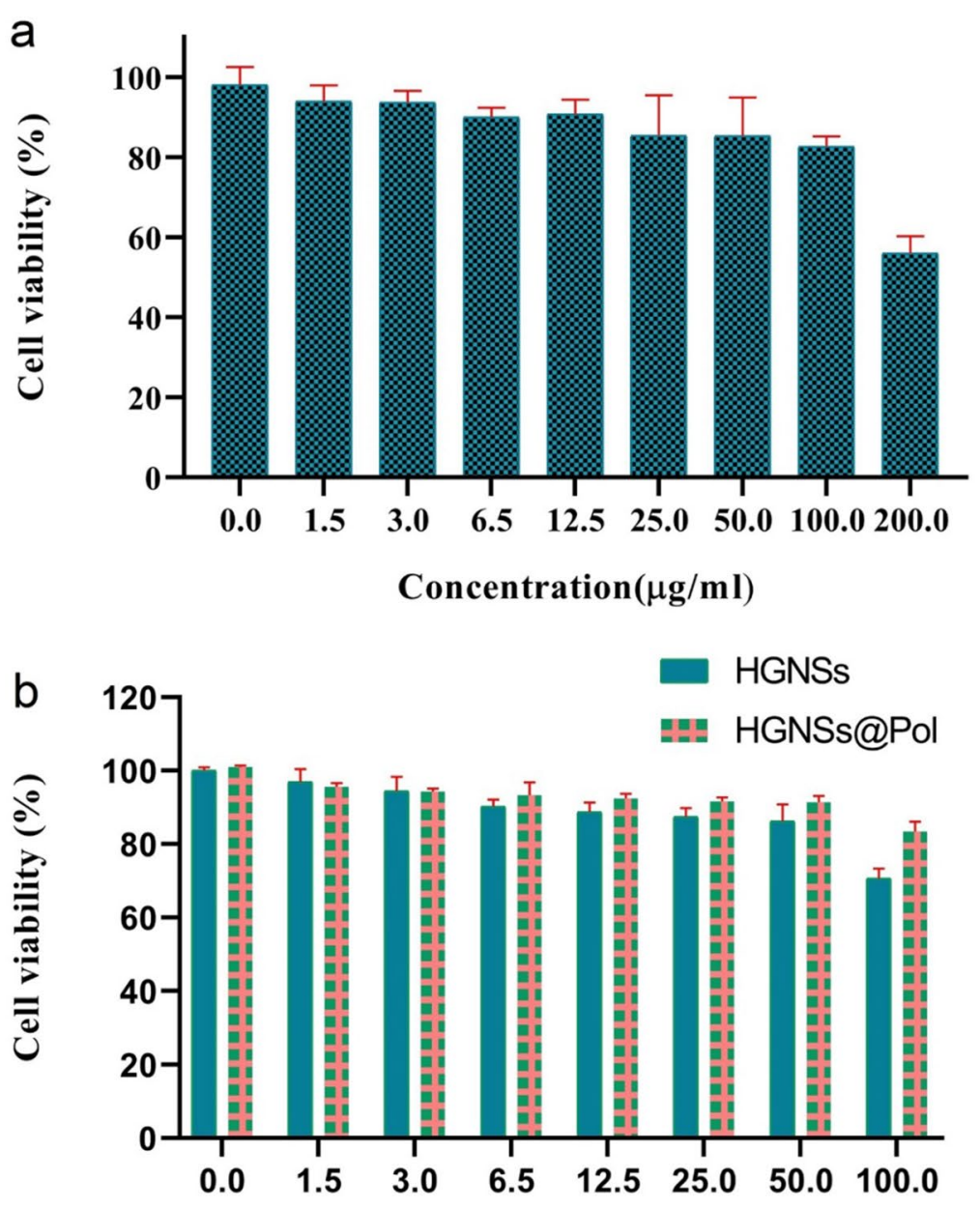

Concentration $(\mu \mathrm{g} / \mathrm{ml})$

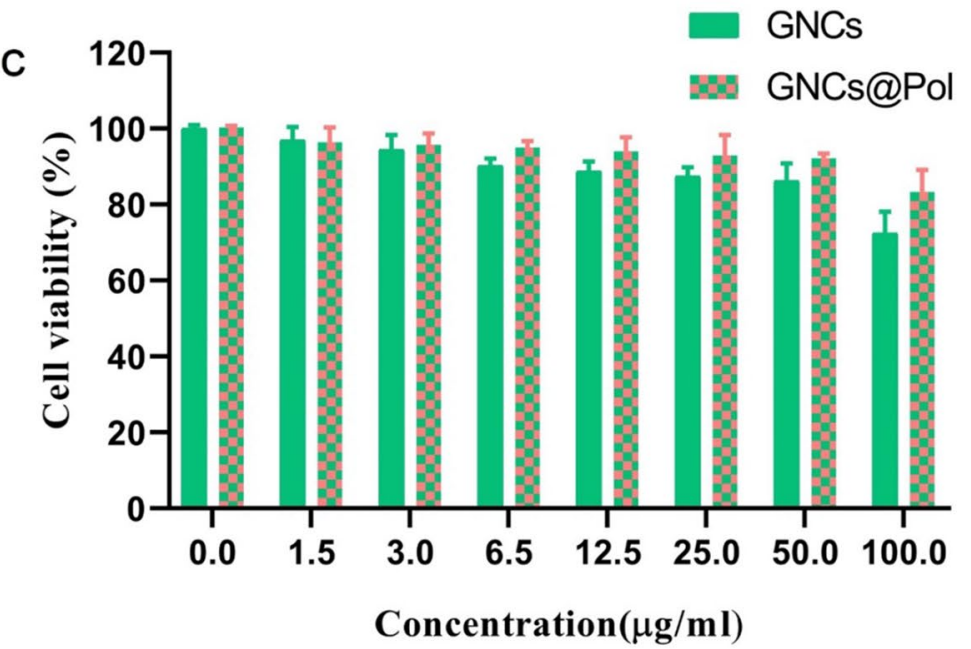

Fig. 10 Cell viability of a ABC triblock micelles, b HGNSs and HGNSs@Pol, c GNCs and GNCs@Pol in different concentrations $\left(1.5,3,6.5,12.5,25,50\right.$, and $\left.100 \mathrm{gg} \mathrm{mL}^{-1}\right)$ over $48 \mathrm{~h}$ treatment of MCF-7 cell line evaluated with MTT assay 
cell viability decreased slightly to $80 \%$ (Rengan 2014). Robinson et al. compared the effect of gold nanorods and nanocages for $48 \mathrm{~h}$ in DU145 cells at optical densities ranging from 0 to 12 . Their results showed that cell viability in GNRs and GNCs treatment groups were not significantly different if CTAB is thoroughly removed from gold nanorods (Robinson et al. 2015).

\section{Cytotoxicity assay by laser irradiation}

Photo/chemo-toxicity of designed GNSs was evaluated in MCF-7 cells by MTT assay. As shown in Fig. 11, GNCs and HGNSs showed slight toxicity (cell viability of GNCs and HGNSs were 72.4 and $70.65 \%$, respectively), and polymer coating decreased the toxicity of nanostructures (cell viabilities reached $\sim 83 \%$ ). In the first monotherapy groups, that received only PTT, cell viability of GNCs@Pol and HGNSs@Pol after NIR irradiation decreased to 45.1 and $41.4 \%$, respectively. In the second monotherapy groups, that received only chemotherapy, cell viability of Dox-loaded GNCs@Pol and HGNSs@Pol without laser irradiation, decreased to $~ 44.4 \%$ and $~ 38.6 \%$, respectively. In combination therapy groups that received chemo-photothermal therapy, cell viability dropped to $14.6 \%$ and 10.2\% for GNCs@Dox-Pol and HGNSs@Dox-Pol, respectively. This high rate of mortality of MCF-7 cells indicates a synergistic effect of PTT and chemotherapy. On the other hand, due to the thermo-sensitivity of our polymer, Dox release was also accelerated by temperature increase due to laser irradiation. It is important to note that the slightly higher mortality rate of HGNSs@DoxPol-L compared to GNCs@Dox-Pol-L was due to the higher cellular uptake of HGNSs (effect of size and morphology, refer to Table 1 and Figs. 2, 3) and higher light to heat conversion efficacy of HGNSs compared to GNCs (Fig. 5). The results obtained by Wang et al. showed that Dox-loaded GNCs@hyaluronic acid upon NIR irradiation, reduced cell viability to $18 \%$ (Wang 2014). Note that the efficacy of hyperthermiatriggered release of Dox under the NIR irradiation indicates an excellent synergistic

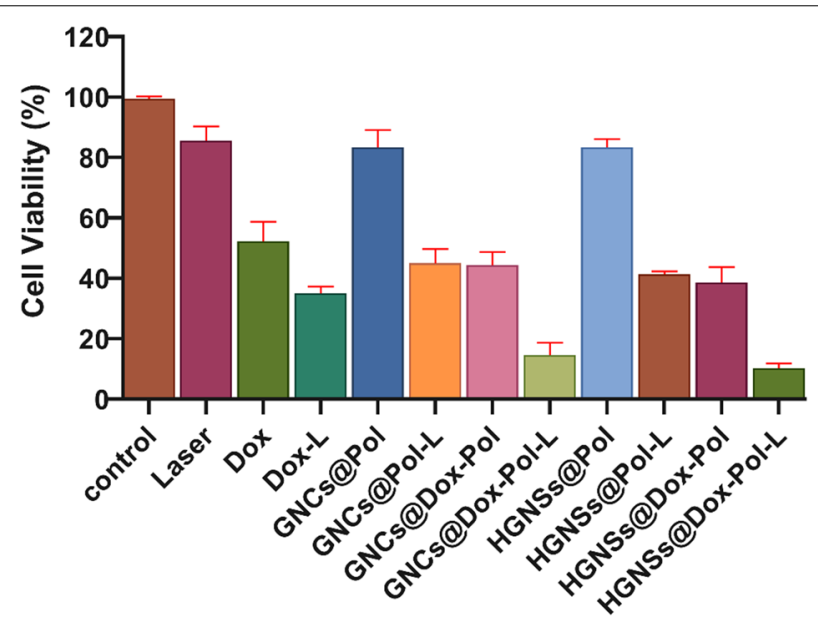

Fig. 11 Cell viability of designed GNSs $\left(100 \mu \mathrm{g} \mathrm{mL}^{-1}\right)$ with and without laser irradiation. Combination therapy groups (HGNSs@Dox-Pol, GNCs@Dox-Pol, with laser irradiation) have the least cell viability in comparison with other groups 
effect in growth inhibition of MCF-7 cells. These results are in accordance with several recent studies (Xia 2011; Rengan 2014).

\section{Induction of apoptosis} Cell cycle arrest

Nanoparticles that are uptaken by cells can interact with cell membranes and dysregulate the cell cycle, and finally induce apoptosis or necrosis (Jones and Grainger 2009). In comparison with monotherapy, the combined PTT and chemotherapy have been reported to synergistically improve therapeutic effects in cancers and reduce side effects by decreasing the dose of toxic chemotherapeutic drugs (Chen 2013). Indeed, if a treatment can stop the cell cycle, it would be effective in cancer therapy (Ling 1996). The SubG0/G1 area is of special interest in many toxicity studies that show the characteristics of apoptosis (Mahmoudi 2011). In this study, we investigated the effects of administration of GNSs@Dox-Pol with/without irradiation on the cell cycle (Fig. 12a). When comparing the cell cycle pattern of non-treated MCF-7 cells (negative control group) compared to those treated with only laser irradiation (positive control group), an arrest was observed in SubG1 and to a lesser extent in S phases. In free Dox, Dox-loaded GNCs@Pol and Dox-loaded HGNSs@Pol treatment group arrest was detected in S and SubG1 phases which proves release of Dox from GNSs@Pol structures. Our results are in line with the previous reports that Dox causes S arrests (Ling 1996; Potter 2002). With laser irradiation to MCF-7 cells treated by GNCs@Pol and HGNSs@Pol, in comparison to the only laser treatment group, the percentage of arrest in SubG1 was increased from $26 \%$ to $~ 42$ and $52 \%$, respectively, which is a sign of cell apoptosis. The increase in the population of cells arrested in Sub G1 proves that GNSs were accumulated in cells that can successfully improve the light to heat energy conversion. Therefore, these GNSs act as transducers in PTT treatment. In cells that received both chemotherapy and PTT in GNSs@ Dox-Pol treatment groups, the percentage of sub G1 cell population was increased drastically. A synergistic effect was observed after the treatment of cells with GNSs@Dox-Pol with laser irradiation. $90.86 \%$ and $82.30 \%$ of cells were shifted to the SubG1 phase after treatment with HGNSs@Dox-Pol + L and GNCs@Dox-Pol + L, respectively.

\section{DAPI staining assay}

Nuclear staining using 4,6-diamidino-2-phenylindole (DAPI) is the well-known standard test for the evaluation of healthy, apoptotic, and necrotic cells through assessment of chromatin morphology and its density (Jafarirad 2018). The cell groups treated with GNSs@Pol in absence of laser exposure and the cells treated with irradiation alone (as positive control) would not induce significant chromatin degradation or cell death. Moreover, free Dox (with the same concentration of loaded groups) and GNSs@Dox-Pol groups did not cause large-scale chromatin degradation, whereas the MCF-7 cells that received combination therapy (GNSs@Dox-Pol and laser) showed tremendous chromatin condensation and fragmentation along with a significant decrease in the cell population. The synergistic effect of combination therapy was more dominant in HGNSs@Dox-Pol+laser compared to GNCs@Dox-Pol+laser. Poursalehi et al. showed that monotherapy on MCF-7 cells (treating with free Dox or Dox-loaded gold nanocomposites without laser exposure) were not able to induce 

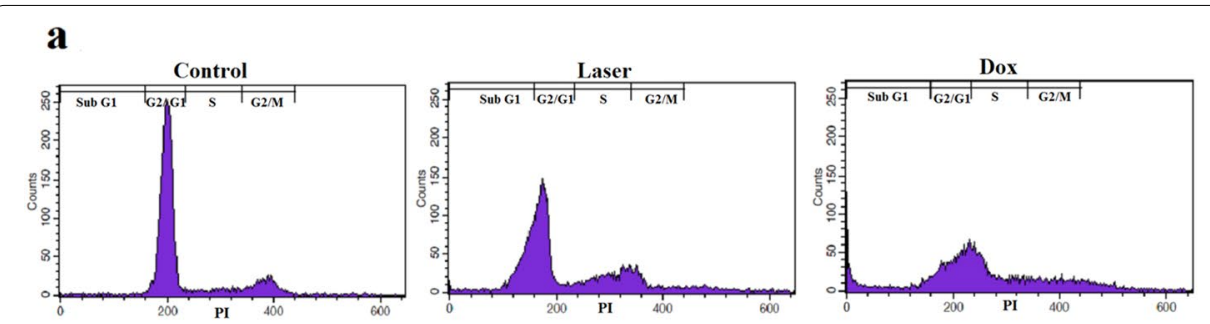

GNCs@Pol+L
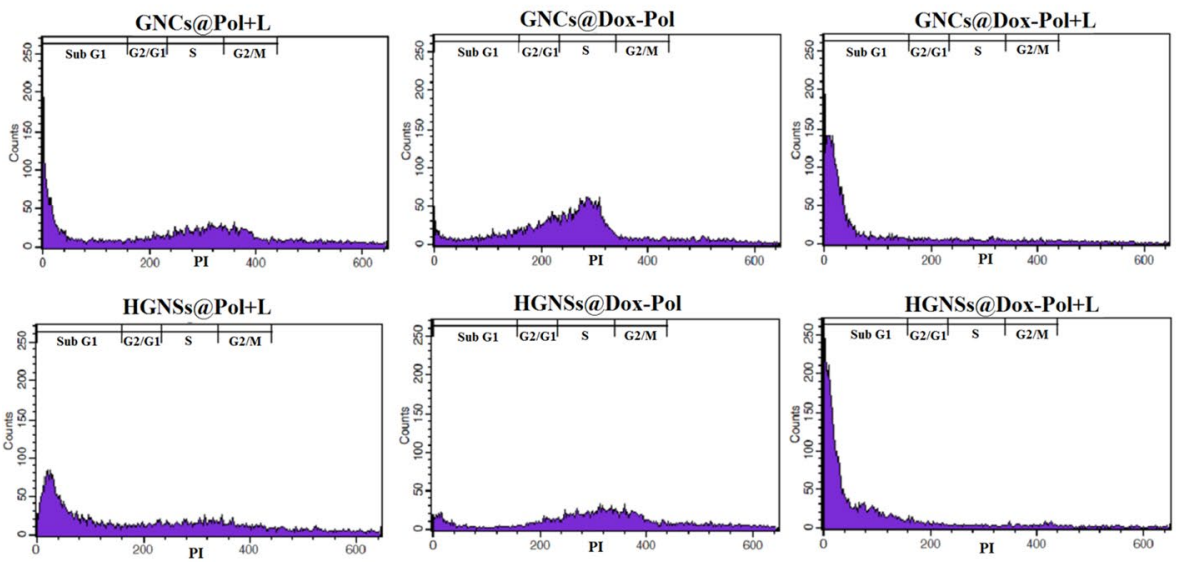

b

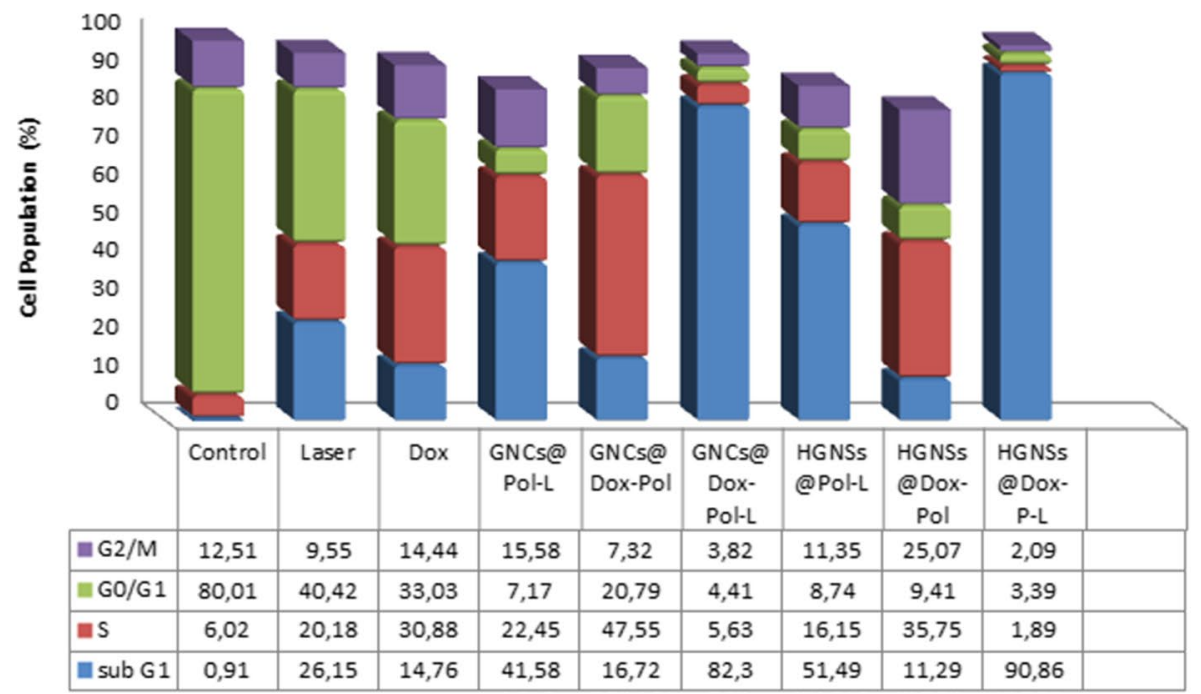

Fig. 12 Cell cycle results. a Percentage of MCF-7 cell distribution in various cell cycle phases after $48 \mathrm{~h}$ treatment with Dox, GNCs@Pol+laser, GNCs@Dox-Pol, GNCs@Dox-Pol+laser, HGNSs@Pol+laser HGNSs@ Dox-Pol, HGNSs@Dox-Pol+ laser. Cells treated with laser only (808 nm, 0.7 W.cm ${ }^{-2}, 10$ min) were considered as positive control and non-treated cells were considered as negative control. b Quantitative results of cell cycle arrest

apoptotic cell death (changes in chromatin morphology and fragmented nucleus) as much as combination therapy (Poursalehi 2019). In another study by Agabeigi et al., MCF-7 cells treated with MTX and FA-loaded $\mathrm{Au} @ \mathrm{SiO}_{2}$ NPs that were exposed to low-level laser irradiations (combination therapy group) induced significantly more 
apoptotic cells, compared to the cells groups that received monotherapy (chemotherapy or PTT alone) (Agabeigi 2020). Another study carried out by Jafarirad et al. showed that MCF-7 cells treated with functionalized $\mathrm{Ag} / \mathrm{ZnO}$ and $\mathrm{Nd} / \mathrm{ZnO}$ reduced graphene oxide nanocomposites which were exposed to low-level laser irradiation were able to induce apoptosis more effectively than cells treated with nanocomposites or laser alone (Jafarirad 2018).

\section{Apoptosis analysis by the flow cytometry method}

In order to have a quantitative evaluation on the effect of GNSs morphology in PTT efficacy, and the combination effect of chemo-PTT on the induction of apoptosis in MCF7 cells, Annexin-V apoptosis assay was done. The greater influence of DNA damage has been ascribed to a stop the replication fork, leading to double-strand breaks production, which reduces cell viability (Agabeigi et al. 2020).

Figure 13 presents the results of the Annexin V-FITC assay. MCF-7 cells treated with HGNSs@Pol and GNCs@Pol with laser irradiation (monotherapy: photothermal treatment group) showed 45 and $35 \%$ of necrotic cells and the viable cells population fall to 53 and 63\%, respectively. The presence of gold nanoparticles as photo-synthesizer is essential in photothermal therapy and HGNSs because of higher cellular uptake and heat generation ability showed more destructive effect than GNCs. In the cells treatment group that received HGNSs@Dox-Pol and GNCs@Dox-Pol without laser irradiation (monotherapy: chemotherapy treatment group), 74 and $59 \%$ of cells showed apoptosis and 26 and 41\% necrosis, respectively. The results indicated that HGNSs@Dox-Pol was more successful in the induction of apoptosis (programmed cell death) compared to GNCs@Dox-Pol may be due to the higher Dox release in cells because of higher cellular uptake of HGNSs@Pol in comparison with GNCs@Pol. MCF-7 cells treated with HGNSs@Dox-Pol-L and GNCs@Dox-Pol-L that received combination therapy (chemo-photothermal therapy) showed the highest apoptosis and lowest necrotic cell death (97.5 and $92.6 \%$ apoptosis and 2.5 and $7.42 \%$ necrosis,

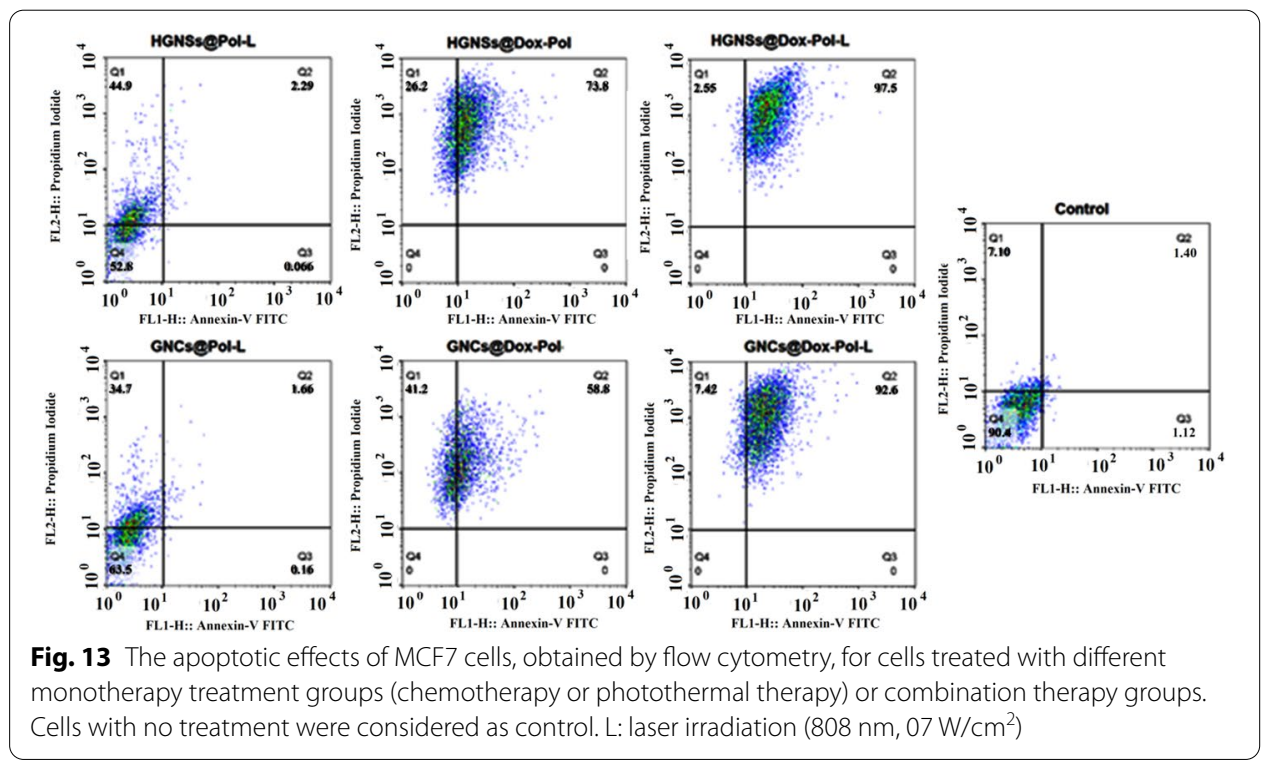


respectively). The maximum apoptosis rate (97\%) was detected in cells treated with HGNSs@Dox-Pol. As a result, the photothermal efficacy of these GNSs was dependent on the morphology of the nanostructure. The results of the apoptosis assay confirmed the results obtained in cell cycle assay (Fig. 12), DAPI staining (Fig. 14) and cell viability assay after laser irradiation (Fig. 11) that all were related to the results obtained in cell uptake and temperature elevation studies (Figs. 8 and 5). The more particles absorbed into the cell, the greater the number of nanoparticles inside the cell that convert the photon energy into heat. This heat generated inside the cell destroys the cell. Also, the efficiency of converting photon energy to heat is another important factor that is completely dependent on the morphology of gold nanoparticles. The higher ability to convert photon energy to heat in a structure, the higher the photothermal efficiency of that structure and the more toxicity is observed (due to the higher intracellular heat production). In this study, both anisotropic gold nanostructures (HGNSs and GNCs) showed high toxicity due to their structural potential for high intracellular heat production and it was slightly better in HGNSs.

\section{Conclusion}

In this work, we investigated combination chemo/PTT therapy with GNCs and HGNSs-coated thermo/pH-sensitive polymers. GNCs and HGNSs were selected for their efficient light to heat transduction and extensive Dox delivering capacity upon

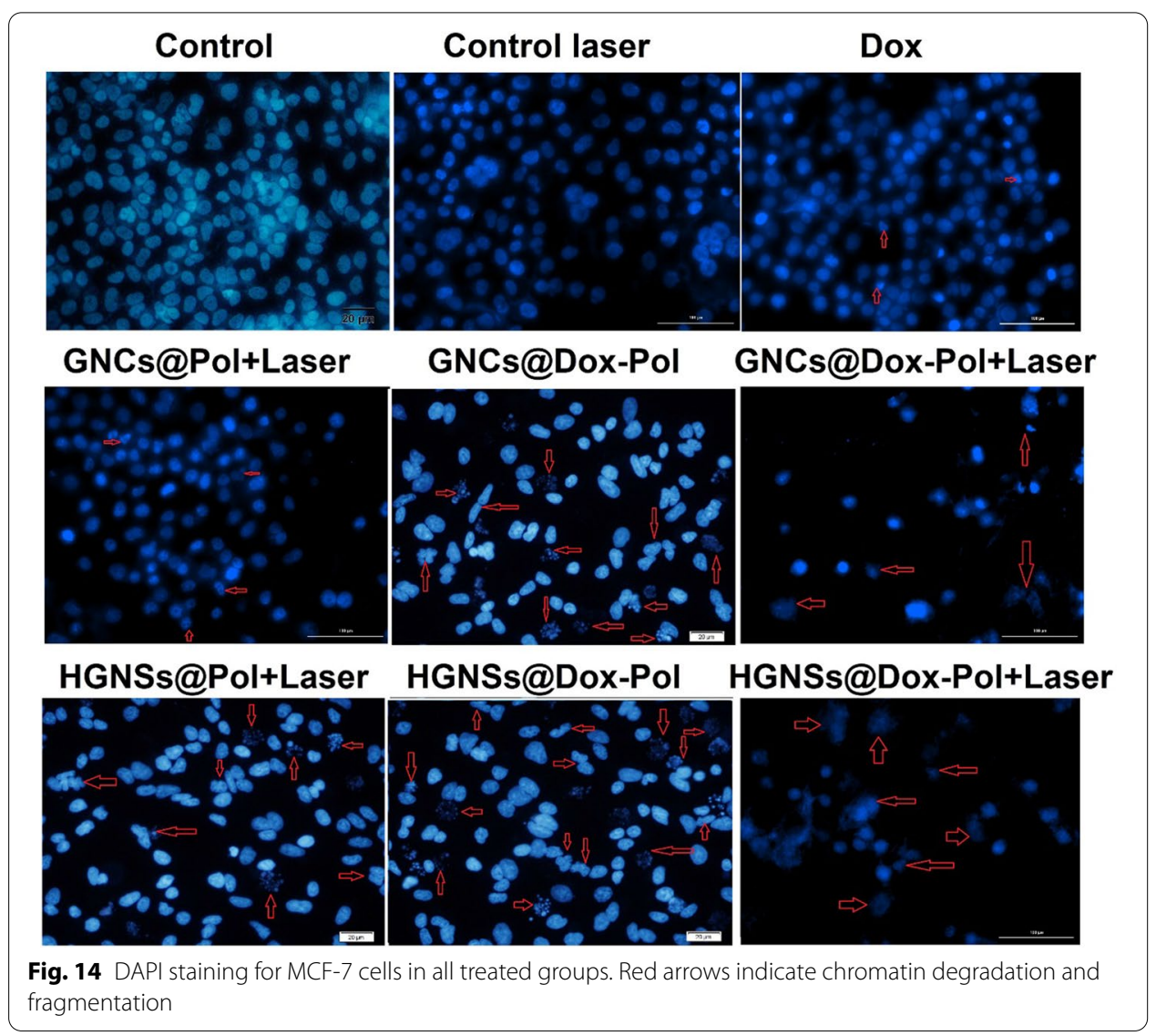


laser irradiation. HGNSs and GNCs were synthesized, coated with PAA-b-PNIPAAmb-PCL-SH, and loaded with Dox. GNSs@Pol has a high capacity to accumulate in MCF-7 cells that were proved by different cell uptake assays. Dox release accelerated in tumor cells acidic environment and under NIR laser irradiation. GNSs@Dox-Pol upon laser irradiation (combination therapy group) increased tunable therapeutic efficacy compared to monotherapy (chemotherapy or PTT alone). The increased population of apoptotic cells was confirmed by DAPI staining, cell cycle studies and Annexin V-PI assays. In combination therapy with both gold nanostructures, hallow gold nanostars showed superior efficacy compared to gold nanocages. Three major reasons may be suggested for this superiority. First, HGNSs had a smaller size than GNCs that raised cellular uptake of HGNSs compared to GNCs. Second, spindle-like morphology of HGNs can lead to superior cellular uptake compared to cube shape GNCs. Accumulation of GNSs in cells has a straight impact on PTT efficacy. Finally, HGNSs has often been advocated as more efficient light absorbers than GNCs due to their branched structure that tuned plasmon resonances.

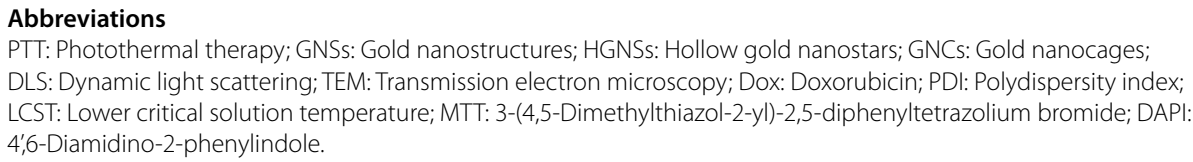

Acknowledgements

Not applicable.

\section{Authors' contributions}

AP: gold nanoparticles synthesis and data collection and figure preparation. MA: conducting in data analysis. FR: contributed to the edition of manuscript. FB: contributed in laser experiments. FM: synthesis of the copolymer. RS: proposal design and ideas, contributed to the cellular tests, data analysis and writing of manuscript. MM: contributed in the organization and writing. All authors read and approved the final manuscript.

\section{Funding}

This project was supported financially by grant number: 59447 from Drug Applied Research Center, Tabriz University of Medical Sciences, Tabriz, Iran.

\section{Availability of data and materials}

Not applicable.

\section{Declarations}

Ethics approval and consent to participate

Not applicable.

Consent for publication

Not applicable.

Competing interests

The authors declare that they have no competing interests.

\section{Author details}

${ }^{1}$ Chemistry Department, Faculty of Science, Azarbaijan Shahid Madani University, Tabriz, Iran. ${ }^{2}$ Department of Medical Nanotechnology, Faculty of Advanced Medical Science, Tabriz University of Medical Science, Tabriz, Iran. ${ }^{3}$ Department of Electrical Engineering, University of Bonab, Bonab, Iran. ${ }^{4}$ Halal Research Center of IRI, FDA, Tehran, Iran. ${ }^{5}$ Drug Applied Research Center and Department of Medical Nanotechnology, Faculty of Advanced Medical Science, Tabriz University of Medical Science, 5166614733 Tabriz, Iran.

Received: 7 March 2021 Accepted: 9 July 2021

Published online: 23 July 2021 


\section{References}

Abbasian M et al (2017) Chemo-photothermal therapy of cancer cells using gold nanorod-cored stimuli-responsive triblock copolymer. New J Chem 41(21):12777-12788

Agabeigi R et al (2020) Novel chemo-photothermal therapy in breast cancer using methotrexate-loaded folic acid conjugated Au@ SiO 2 nanoparticles. Nanoscale Res Lett 15(1):1-14

Blagosklonny MV (2004) Analysis of FDA approved anticancer drugs reveals the future of cancer therapy. Cell Cycle 3(8):1033-1040

Cabral RM, Baptista PV (2013) The chemistry and biology of gold nanoparticle-mediated photothermal therapy: promises and challenges. Nano Life 3(03):1330001

Chaudhuri P et al (2009) Fullerenol-cytotoxic conjugates for cancer chemotherapy. ACS Nano 3(9):2505-2514

Chekhun $V$ et al (2009) The use of nanoferromagnetics to increase the cytotoxic effect of antitumor drugs. Exp Oncol 31(3):163-167

Chen J et al (2007) Immuno gold nanocages with tailored optical properties for targeted photothermal destruction of cancer cells. Nano Lett 7(5):1318-1322

Chen $\mathrm{H}$ et al (2013) Multifunctional gold nanostar conjugates for tumor imaging and combined photothermal and chemotherapy. Theranostics 3(9):633

Cobley CM et al (2010) Targeting gold nanocages to cancer cells for photothermal destruction and drug delivery. Expert Opin Drug Deliv 7(5):577-587

Dianat-Moghadam H et al (2018) Cancer stem cells-emanated therapy resistance: Implications for liposomal drug delivery systems. J Control Release 288:62-83

Dianat-Moghadam $\mathrm{H}$ et al (2020) TRAIL in oncology: from recombinant TRAIL to nano- and self-targeted TRAlL-based therapies. Pharmacol Res 155:104716

Ding C, Li Z (2017) A review of drug release mechanisms from nanocarrier systems. Mater Sci Eng, C 76:1440-1453

Dykman L, Khlebtsov N (2012) Gold nanoparticles in biomedical applications: recent advances and perspectives. Chem Soc Rev 41(6):2256-2282

Dykman LA, Khlebtsov NG (2014) Uptake of engineered gold nanoparticles into mammalian cells. Chem Rev 114(2):1258-1288

Gao L et al (2012) Hypocrellin-loaded gold nanocages with high two-photon efficiency for photothermal/photodynamic cancer therapy in vitro. ACS Nano 6(9):8030-8040

Gharatape A et al (2016) A novel strategy for low level laser-induced plasmonic photothermal therapy: the efficient bactericidal effect of biocompatible AuNPs@(PNIPAAM-co-PDMAEMA, PLGA and chitosan). RSC Adv 6(112):110499-110510

Halas NJ (2010) Plasmonics: an emerging field fostered by nano letters. Nano Lett 10(10):3816-3822

Hao F et al (2007) Plasmon resonances of a gold nanostar. Nano Lett 7(3):729-732

Hauck TS et al (2008) Enhancing the toxicity of cancer chemotherapeutics with gold nanorod hyperthermia. Adv Mater 20(20):3832-3838

Honary S, Zahir F (2013) Effect of zeta potential on the properties of nano-drug delivery systems-a review (Part 2). Trop J Pharm Res 12(2):265-273

Hou S et al (2016) Quantitative differentiation of cell surface-bound and internalized cationic gold nanoparticles using mass spectrometry. ACS Nano 10(7):6731-6736

Jafarirad S et al (2018) A novel non-invasive strategy for low-level laser-induced cancer therapy by using new Ag/ $\mathrm{ZnO}$ and $\mathrm{Nd} / \mathrm{ZnO}$ functionalized reduced graphene oxide nanocomposites. Artif Cells Nanomed Biotechnol 46(sup2):800-816

Jaffray DA (2012) Image-guided radiotherapy: from current concept to future perspectives. Nat Rev Clin Oncol 9(12):688

Jalilzadeh $\mathrm{N}$ et al (2020) novel nano-vehicle for delivery and efficiency of anticancer auraptene against colon cancer cells. Sci Rep 10(1):1-19

Jang $\mathrm{H}$ et al (2014) Facile synthesis and intraparticle self-catalytic oxidation of dextran-coated hollow Au-Ag nanoshell and its application for chemo-thermotherapy. ACS Nano 8(1):467-475

Jiang Y et al (2015) The interplay of size and surface functionality on the cellular uptake of sub-10 nm gold nanoparticles. ACS Nano 9(10):9986-9993

Jones CF, Grainger DW (2009) In vitro assessments of nanomaterial toxicity. Adv Drug Deliv Rev 61 (6):438-456

Kang S et al (2015) Mesenchymal stem cells aggregate and deliver gold nanoparticles to tumors for photothermal therapy. ACS Nano 9(10):9678-9690

Khan SA et al (2012) A gold nanocage-CNT hybrid for targeted imaging and photothermal destruction of cancer cells. Chem Commun 48(53):6711-6713

Khlebtsov BN et al (2013) A simple Mie-type model for silica-coated gold nanocages. J Quant Spectrosc Radiat Transfer 121:23-29

Lara-Cruz C et al (2019) Gold nanoparticle uptake is enhanced by estradiol in MCF-7 breast cancer cells. Int J Nanomed 14:2705

Li W et al (2011) Gold nanocages covered with thermally-responsive polymers for controlled release by high-intensity focused ultrasound. Nanoscale 3(4):1724-1730

Li SW et al (2013) Positive effect of high RKIP expression on reduced distant metastasis by chemotherapy when combined with radiotherapy in locoregionally advanced nasopharyngeal carcinoma: a prospective study. Med Oncol 30(1):322

Liao J et al (2015) Combined cancer photothermal-chemotherapy based on doxorubicin/gold nanorod-loaded polymersomes. Theranostics 5(4):345

Ling Y-H et al (1996) Cell cycle-dependent cytotoxicity, G2/M phase arrest, and disruption of p34cdc2/cyclin B1 activity induced by doxorubicin in synchronized P388 cells. Mol Pharmacol 49(5):832-841

Liu Y et al (2015) A plasmonic gold nanostar theranostic probe for in vivo tumor imaging and photothermal therapy. Theranostics 5(9):946 
Mahmoodzadeh F et al (2017) A novel dual stimuli-responsive thiol-end-capped ABC triblock copolymer: synthesis via reversible addition-fragmentation chain transfer technique, and investigation of its self-assembly behavior. Polym Int 66(11):1651-1661

Mahmoudi M et al (2011) Effect of nanoparticles on the cell life cycle. Chem Rev 111(5):3407-3432

Melancon MP, Zhou M, Li C (2011) Cancer theranostics with near-infrared light-activatable multimodal nanoparticles. Acc Chem Res 44(10):947-956

Moustaoui $\mathrm{H}$ et al (2019) Shape and size effect on photothermal heat elevation of gold nanoparticles: absorption coefficient experimental measurement of spherical and urchin-shaped gold nanoparticles. J Phys Chem C 123(28):17548-17554

Mura S, Nicolas J, Couvreur P (2013) Stimuli-responsive nanocarriers for drug delivery. Nat Mater 12(11):991-1003

Nam J et al (2013) pH-responsive assembly of gold nanoparticles and "spatiotemporally concerted" drug release for synergistic cancer therapy. ACS Nano 7(4):3388-3402

Potter AJ et al (2002) Flow cytometric analysis of the cell cycle phase specificity of DNA damage induced by radiation, hydrogen peroxide and doxorubicin. Carcinogenesis 23(3):389-401

Poursalehi Z et al (2019) A simple strategy for chemo-photothermal ablation of breast cancer cells by novel smart gold nanoparticles. Photodiagn Photodyn Ther 28:25-37

Rahimi M, Safa KD, Salehi R (2017) Co-delivery of doxorubicin and methotrexate by dendritic chitosan-g-mPEG as a magnetic nanocarrier for multi-drug delivery in combination chemotherapy. Polym Chem 8(47):7333-7350

Rahimi M et al (2017) Dendritic chitosan as a magnetic and biocompatible nanocarrier for the simultaneous delivery of doxorubicin and methotrexate to MCF-7 cell line. New J Chem 41(8):3177-3189

Rengan AK et al (2014) Gold nanocages as effective photothermal transducers in killing highly tumorigenic cancer cells. Part Part Syst Charact 31(3):398-405

Robinson R, Gerlach W, Ghandehari H (2015) Comparative effect of gold nanorods and nanocages for prostate tumor hyperthermia. J Control Release 220:245-252

Salehi R, Rasouli S, Hamishehkar H (2015) Smart thermo/pH responsive magnetic nanogels for the simultaneous delivery of doxorubicin and methotrexate. Int J Pharm 487(1-2):274-284

Seo JR et al (2018) Facile synthesis of surfactant-free au decorated hollow silica nanoparticles for photothermal applications. Macromol Res 26(12):1129-1134

Skrabalak SE et al (2007) Facile synthesis of Ag nanocubes and Au nanocages. Nat Protoc 2(9):2182-2190

Sonavane G, Tomoda K, Makino K (2008) Biodistribution of colloidal gold nanoparticles after intravenous administration: effect of particle size. Colloids Surf, B 66(2):274-280

Sun $\mathrm{H}$ et al (2017) Cancer cell membrane-coated gold nanocages with hyperthermia-triggered drug release and homotypic target inhibit growth and metastasis of breast cancer. Adv Func Mater 27(3):1604300

Van de Broek B et al (2011) Specific cell targeting with nanobody conjugated branched gold nanoparticles for photothermal therapy. ACS Nano 5(6):4319-4328

Wang W et al (2012) Facile synthesis of hollow urchin-like gold nanoparticles and their catalytic activity. Gold Bull 45(2):91-98

Wang Y et al (2013) Comparison study of gold nanohexapods, nanorods, and nanocages for photothermal cancer treatment. ACS Nano 7(3):2068-2077

Wang $Z$ et al (2014) A multi-stimuli responsive gold nanocage-hyaluronic platform for targeted photothermal and chemotherapy. Biomaterials 35(36):9678-9688

Wang $\mathrm{H}$ et al (2015) Facile preparation of gold nanocages and hollow gold nanospheres via solvent thermal treatment and their surface plasmon resonance and photothermal properties. J Colloid Interface Sci 440:236-244

Xia Y et al (2011) Gold nanocages: from synthesis to theranostic applications. Acc Chem Res 44(10):914-924

Xiang Y et al (2017) Recent development of synthetic nonviral systems for sustained gene delivery. Drug Discov Today 22(9):1318-1335

Yang $\mathrm{H}$ et al (2013) Micelles assembled with carbocyanine dyes for theranostic near-infrared fluorescent cancer imaging and photothermal therapy. Biomaterials 34(36):9124-9133

Yap TA, Omlin A, De Bono JS (2013) Development of therapeutic combinations targeting major cancer signaling pathways. J Clin Oncol 31(12):1592-1605

Yavuz MS et al (2009) Gold nanocages covered by smart polymers for controlled release with near-infrared light. Nat Mater 8(12):935-939

Zheng T et al (2016) Gold-nanosponge-based multistimuli-responsive drug vehicles for targeted chemo-photothermal therapy. Adv Mater 28(37):8218-8226

Zhou Y et al (2015) A study on the hemocompatibility of dendronized chitosan derivatives in red blood cells. Drug Des Dev Ther 9:2635

\section{Publisher's Note}

Springer Nature remains neutral with regard to jurisdictional claims in published maps and institutional affiliations. 